\title{
Nanomechanics of cells and biomaterials studied by atomic force microscopy
}

Atomic force microscopy is an indispensable tool for nanomechanical measurements of cells, cell microenvironments, and biomaterials. The mechanical properties of cells and their function are influenced by the elasticity of the extracellular matrix. Thus, understanding the nanomechanical properties is key for tissue engineering applications.

DOI: $\underline{10.1002 / \mathrm{adhm} .201500229}$

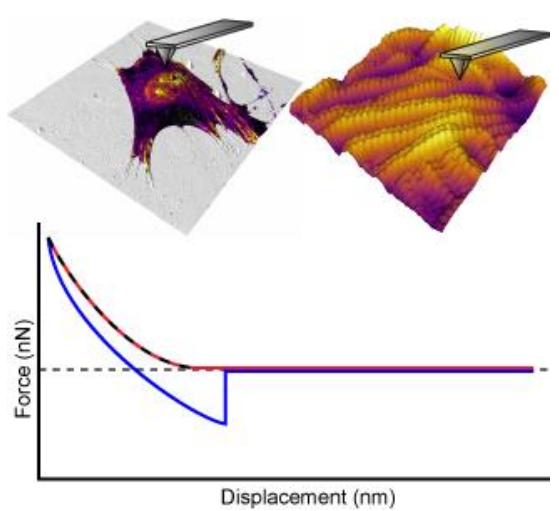

Dr. Jason I. Kilpatrick

Conway Institute of Biomolecular and Biomedical Research, University College Dublin, Belfield, Dublin 4, Ireland

E-mail: Jason.Kilpatrick@ucd.ie

Dr. Irène Revenko

Asylum Research, an Oxford Instruments Company, 6310 Hollister Avenue, Santa Barbara, CA 93117, USA

E-mail: Irene.Revenko@oxinst.com

Dr. Brian J. Rodriguez

Conway Institute of Biomolecular and Biomedical Research, University College Dublin, Belfield, Dublin 4, Ireland

School of Physics, University College Dublin, Belfield, Dublin 4, Ireland E-mail: Brian.Rodriguez@ucd.ie

Keywords: cell elasticity, nanomechanics, biomaterials, atomic force microscopy, tissue engineering

The behavior and mechanical properties of cells are strongly dependent on the biochemical and biomechanical properties of their microenvironment. Thus, understanding the mechanical properties of cells, extracellular matrices, and biomaterials is key to understanding cell function and to develop new materials with tailored mechanical properties for tissue engineering and regenerative medicine applications. Atomic force microscopy (AFM) has emerged as an indispensable technique for measuring the mechanical properties of biomaterials and cells with high spatial resolution and force sensitivity within physiologically relevant environments and timescales in the $\mathrm{kPa}$ to $\mathrm{GPa}$ elastic modulus range. The growing interest in this field of bionanomechanics has been accompanied by an expanding array of models to describe the complexity of indentation of hierarchical biological samples. Furthermore, the integration of AFM with optical microscopy techniques has further opened the door to a wide range of mechanotransduction studies. In recent years, new multidimensional and multiharmonic AFM approaches for mapping mechanical properties have been developed, which allow for rapid determination of, e.g., cell elasticity. This review provides an introduction and practical guide to making AFM-based nanomechanical measurements of cells and surfaces for tissue engineering applications. 


\section{Introduction}

Tissue engineering and regeneration approaches focus on providing tailored substrates or scaffolds to cells that best mimic in vivo topographical, mechanical, and chemical microenvironments. ${ }^{[1]}$ Extracellular matrix (ECM) stiffness in particular has been shown to influence cell shape, adhesion, viability, motility, proliferation, function, and differentiation. ${ }^{[2-}$ ${ }^{12]}$ Thus, cells dynamically sense and respond to mechanical stimuli. ${ }^{[6,13-17]}$ The forces generated by cells depend on and are proportional to the elasticity of the $\mathrm{ECM},{ }^{[18,19]}$ and are mediated by the cytoskeleton and other mechanisms, ${ }^{[7,11,14,20]}$ the regulation of which is an active area of research. ${ }^{[21-26]}$ Given the importance of the role of ECM elasticity and structure on cell behavior $^{[27]}$ and the implications for regenerative medicine and drug delivery, ${ }^{[1]}$ there is a need for techniques to characterize the structure and elasticity of native and engineered ECMs and the effects these factors have on cell properties and function. Ideally, these techniques should be able to access structure and property information across multiple lengthscales, from the cellular level to the lengthscale at which cells 'feel' their environment, i.e., $\leq$ microns up to complex hierarchical structures, make measurements within physiologically relevant timescales, and assess mechanical properties across a wide elastic modulus range (Figure 1). ${ }^{[28]}$

Atomic force microscopy (AFM) is a technique that meets these criteria providing both structural and mechanical information with high spatial resolution and force sensitivity within physiologically relevant timescales in the $\mathrm{kPa}$ to GPa elastic modulus range. As such, AFM has emerged as a quintessential technique for measuring mechanical properties of biomaterials and cells. ${ }^{[29-35]}$ A search of Scopus using the keywords "AFM, elasticity, and cell" shows a growing trend in both publications and citations (Figure 2).

In fact, AFM has long been an enabling tool for the investigation of biological systems, which in turn has been a driving force for the development of AFM instrumentation and techniques. ${ }^{[36-38]}$ Early applications of AFM in biology focused on imaging DNA, membranes, proteins, lipids, and cell surfaces. ${ }^{[36]}$ Contact mode force measurements and amplitude 
modulation mode phase imaging were subsequently developed and used to elucidate the nanomechanical properties of DNA and other biomolecules. ${ }^{[37,39,40]}$ Nowadays, AFM has become increasingly sophisticated, e.g., AFM can be applied to investigate friction ${ }^{[41]}$ of biomimetic hydrogels, ${ }^{[42]}$ probe electrostatic and electromechanical properties of biomaterials, ${ }^{[43]}$ measure extensibility of fibrin fibers ${ }^{[44]}$ and intermediate filaments, ${ }^{[45]}$ map molecular recognition sites on cells, ${ }^{[46]}$ perform nanoscale surgeries on live cells, ${ }^{[47]}$ measure mitotic cell rounding forces, ${ }^{[48-50]}$ visualize the DNA double helix structure,${ }^{[51,52]}$ and observe the molecular motor myosin walking on actin in real-time. ${ }^{[53]}$ Force spectroscopy has been applied to understand, e.g., molecular interactions, ${ }^{[54-57]}$ protein unfolding, ${ }^{[58-63]}$ cell-cell ${ }^{[39]}$ and cell-substrate $^{[64]}$ adhesion, and to spatially map perturbations of hydration layers at the GroELwater interface with high resolution. ${ }^{[65]}$ All of these AFM applications have implications for the continuing development of biomedicine and further information can be found in a number of excellent review articles. ${ }^{[66-69]}$ Given the role mechanics plays in determining biofunction and human health, including the effects of mechanical forces on lung function (cyclic forces due to breathing, oscillatory stresses) ${ }^{[70]}$ and tumor-cell migration, ${ }^{[71,72]}$ there is an ongoing need to understand and probe the mechanical properties of cells and their environments with cellular and subcellular resolution under physiologically relevant conditions. This review is intended to serve as an introduction and practical guide to making AFM-based nanomechanical measurements of cells and surfaces for tissue engineering applications, highlighting several key examples and recent advances in the field.

\section{Method}

\subsection{Atomic Force Microscopy}

AFM has been an enabling technology in a range of fields, ${ }^{[73]}$ including mechanobiology and biomaterials characterization. ${ }^{[66,67]}$ In AFM, typically a sharp tip at the end of a microfabricated cantilever is used to probe tip-sample interaction forces (Figure 3). An optical lever detection system is employed to monitor the interaction forces; i.e., a laser beam is 
reflected off the backside of the cantilever and into a position sensitive photodiode, which is used to determine changes in deflection by tracking the position of the reflected laser beam. As the tip is raster scanned relative to the sample (depending on the AFM used, the tip or the sample is scanned), changes in the interaction force can be monitored and used to construct an image of the surface. AFM can be operated in static (contact mode) or dynamic modes (e.g., amplitude modulation, frequency modulation) and can be used to image biological samples under controlled conditions (e.g., liquid, ion concentration, $\mathrm{pH}$, temperature) making it an ideal tool for the study of biological systems under conditions that mimic the in vivo environment. AFM force-distance measurements (Figure 3b) are widely used to measure mechanical properties and both pyramidal (Figure 3c) and spherical (Figure 3d) tips can be used, however, the latter has an adverse effect on resolution. The lateral resolution of AFM depends primarily on the size of the tip-sample contact, the degree of sample deformation and the lengthscale of any surface forces present. An AFM image of articular cartilage recorded using a standard microfabricated pyramidal AFM tip is shown in Figure 3e, and for comparison, an image recorded using a spherical tip is shown in Figure 3f, demonstrating the impact of tip-sample contact size on lateral resolution. ${ }^{[74]}$ Comparisons between AFM and other techniques for probing mechanical properties can be found in refs. ${ }^{[75-79]}$.

A popular trend in AFM cell studies is to couple AFM with optical techniques. ${ }^{[48-50,80-}$ ${ }^{83]}$ This combination is complementary since optical images usually have a larger field of view than the area accessible by AFM, making it easier to position the AFM tip at a precise location over a cell and to provide context to any AFM data obtained. Many publications show AFM data combined with fluorescent data, ${ }^{[84-86]}$ e.g., Bray et al. used the AFM tip to indent a cardiomyocyte with a controlled force and the flow of fluorescently labeled $\mathrm{Ca}^{2+}$ inside the cell was recorded optically. ${ }^{[87]}$ Geisse et al. used patterned fibronectin substrates to confine cardiomyocytes, visualizing the cell topography with AFM and the cytoskeletal remodeling using fluorescence microscopy (see Figure 4). This type of combined instrumentation has also 
been used to visualize the stimulation of nitric oxide mechanotransduction in osteoblasts ${ }^{[88]}$ and actin filaments with fluorescent markers while investigating the effect of anti-cytoskeleton drugs on cell elasticity. ${ }^{[89]}$

\subsection{Force-Distance Curves}

A general feature of AFM modes used to determine the mechanical properties of a sample though indentation is that they ultimately rely on the determination of a force vs. distance relationship. Here, either the cantilever base or the sample is moved by a piezoelectric actuator vertically ( $\mathrm{Z}$ axis) such that the tip-sample gap decreases until contact occurs and the cantilever tip experiences a repulsive force causing it to deflect whilst indenting the sample of interest (see Figure 3). The maximum force applied during indentation is determined by either the predefined path of the $\mathrm{Z}$ piezo extension or a maximum force level that is used as a trigger to reverse the direction of the $\mathrm{Z}$ piezo motion. The force is plotted as a function of piezo displacement (see Figure 5).

Force-distance curves are typically composed of a number of regions of interest: A flat baseline where the cantilever is far from the sample surface and there is zero force detected; the point of contact (POC) between the tip and the surface; loading of the tip and indentation into the sample; the turnaround point where the direction of the $\mathrm{Z}$ motion is reversed; adhesion where the tip is bound to the sample surface beyond the POC as the tip-sample contact is pulled apart; and a return to zero interaction force at large separations. Long-range forces between the tip and sample (e.g., electrostatics, hydrodynamics) can occur on approach prior to the POC. If the force gradient exceeds the restoring force of the cantilever then a 'jump to contact' can occur close to the surface (not shown) where the cantilever is mechanically unstable and no information can be extracted. Both long-range forces and cantilever instabilities complicate the determination of the POC, the implications of which are discussed later. From each force curve, maximum force, adhesion force, work of adhesion, sample elastic modulus (typically, Young's modulus is measured in AFM experiments), and indentation depth can be measured. As with 
instrumented nanoindentation, ${ }^{[90]}$ it is also possible to measure storage modulus, loss modulus, and phase angle with AFM by implementing a dynamic drive signal during the indentation. ${ }^{[91]}$ These parameters can be used to determine instantaneous modulus, equilibrium modulus, and viscosity. ${ }^{[92]}$ Since AFM requires that the cantilever is inclined relative to the sample, any indentation is not entirely normal to the surface. This may induce lateral motion during indentation, which complicates data interpretation compared to instrumented nanoindentation where motion is constrained to the vertical axis. ${ }^{[93]}$

Whilst most of the values of interest can be read directly from a force-distance curve, the determination of the elastic modulus of a sample requires application of a model that describes the change in contact area as a function of indentation depth as determined by the shape of the indenter used. The simplest of these models is the Hertz model, ${ }^{[94]}$ which describes a sphere indenting an infinite flat surface with a purely elastic interaction:

$$
f_{\text {sphere }}=\frac{4}{3} \frac{E}{1-v^{2}} \sqrt{R} \delta^{3 / 2}
$$

where $f$ is the force, $E$ is the Young's modulus, $v$ is the Poisson's ratio, $R$ is the sphere radius, and $\delta$ is the indentation depth. For a cone geometry indenting an infinite flat surface, the Sneddon model ${ }^{[95]}$ can be used

$$
f_{\text {cone }}=\frac{2}{\pi} \frac{E}{1-v^{2}} \tan \alpha \delta^{2}
$$

where $\alpha$ is the cone half angle. Both of these models employ a list of assumptions: ${ }^{[96]}$ i) the material properties of the sample and the tip are isotropic and homogeneous; ii) the normal contact of the tip and sample is adhesionless and frictionless and the contact geometry is axisymmetric, smooth, and continuous; iii) the deformation of the tip is assumed to be negligible and; iv) the models neglect plasticity, viscoelasticity, pileup, and/or anisotropy. The range of microfabricated cantilevers available generally limits the ability of AFM techniques to measure modulus to a $\mathrm{kPa}$ to $\mathrm{GPa}$ range. 
Most commercially available AFM cantilevers incorporate a microfabricated tip with a pyramidal body and slightly rounded apex. As such, there is usually a transition in the applicability of the above models as a function of indentation depth, with the Hertz model being more appropriate for very small indentations where the contact is approximately spherical and the Sneddon model for larger indentations where a conical geometry is a closer approximation. Other authors have combined these models to create blunt ${ }^{[97,98]}$ and truncated cone ${ }^{[98]}$ formulations that ensure validity for all indentation depths.

When adhesion is present, these models must be modified in order for the modulus values to be accurate. Common modifications include Derjaguin-Muller-Toporov (DMT), ${ }^{[99]}$ Johnson-Kendall-Roberts $(\mathrm{JKR}),{ }^{[100]}$ and Maugis-Dugdale (MD), ${ }^{[101,102]}$ which each treat adhesion differently. JKR theory describes the case of large adhesive force where the contact size is large compared to the indentation depth. DMT describes weak adhesive forces where the contact size is small compared to the indentation depth and MD is an intermediate case where some negative indentation is permitted due to the adhesive force (dependent on sample modulus). ${ }^{[103]}$ There are also other more complex treatments of adhesive forces available in the literature. For a review see ref. ${ }^{[104]}$. Johnson and Greenwood provide a guide which allows for the selection of the appropriate model for an indentation based upon the calculation of the Maugis parameter ${ }^{[101]}$ and the nondimensional load. ${ }^{[105]}$

A range of extended indentation models beyond those traditionally used to describe contact mechanics have been proposed in the literature to deal with the complexity exhibited by biological systems at the nanoscale. Iyer et al. described modifications to include long-range forces due to pericellular brush layers present at the cell surfaces and observed differences between cancerous and normal cells. ${ }^{[106]}$ Models have also been formulated to remove the influence of a rigid substrate when indenting thin compliant samples such as the lamellipodia and filopodia of cells ${ }^{[107]}$ for both adherent and non-adherent cases. ${ }^{[91]}$ Other models such as the Tatara model have been developed for large strain indentation and have been applied to the 
indentation of proteins ${ }^{[108]}$ and cartilage,$^{[109]}$ whilst the Oliver-Pharr method ${ }^{[110]}$ has been used to study the modulus of bone. ${ }^{[11]}$ For a review of non-continuum based models see ref. ${ }^{[12]}$.

The assumption that the material being indented is isotropic and homogeneous is a poor description of biological systems such as cells and other hierarchical biological materials, e.g., bone. In order to more accurately describe this anisotropy, multi-regime analysis (MRA) has been developed, which treats the various elements of the biological system as discrete elements in series. ${ }^{[113]}$ Another approach adopted in the literature is the development of specific models for the treatment of thin walled microcapsules as an analogous model for the indentation of cells. ${ }^{[96,114,115]}$

Cells are inherently viscoelastic at physiological timescales, ${ }^{[116]}$ which can complicate interpretation of indentation data. This behavior was first observed by amplitude modulation AFM (commonly called tapping mode ${ }^{\mathrm{TM}}$, intermittent content, or AC mode $)^{[117,118]}$ where cells were observed to stiffen when probed at microsecond timescales. In order to overcome these limitations, indentation experiments are generally conducted sufficiently slowly to be considered under quasi-equilibrium conditions or at a specific set of velocities such that the contribution of viscoelasticity can be quantified. ${ }^{[91,119-121]}$ Interpretation of viscoelastic properties requires the application of Kelvin-Voigt/Maxwell/Burgers models. ${ }^{[122]}$

Despite the existence of a range of advanced models for the analysis of AFM indentation of biological systems, the Hertz and Sneddon models dominate the literature due to their simplicity and widespread implementation in AFM analysis software packages.

\subsection{Practical Guide}

Biological materials such as cells, native and engineered ECMs are complex hierarchical materials which can exhibit dramatically different moduli over multiple lengthscales and timescales. As such, mechanical characterization to obtain a single modulus number that is representative of a sample is often infeasible. ${ }^{[112]}$ Despite this difficulty, it is not uncommon to find reports of mechanical properties of biomaterials determined by AFM based 
on improper experimental methods and the application of inappropriate models, which are either incorrect or irrelevant to the chosen application. Most studies make comparisons to previously published cell mechanics data rather than assessing the validity of the models applied and experimental parameters used. ${ }^{[12]}$

The determination of the elastic modulus of cells is fraught with a range of difficulties; live cells are dynamic structures that respond to substrate stiffness, ${ }^{[123]}$ surface chemistry, ${ }^{[3]}$ time seeded on a surface, ${ }^{[124]}$ chemical cues from their environment, ${ }^{[125]}$ mechanical history,${ }^{[126]}$ progression through the cell cycle, ${ }^{[127]}$ and cell death. ${ }^{[128]}$ Some studies try and remove these time dependent phenomena by fixing cells before mechanical analysis but this increases the modulus of a cell by orders of magnitude over physiological values. ${ }^{[96]}$ In addition there is complexity arising from the presence of the nucleus and stiff cytoskeletal elements, ${ }^{[129]}$ which transmit applied forces over large distances to focal adhesions. ${ }^{[14]}$ Unless all of these properties are taken into consideration when analyzing indentation data, it is likely that any interpretation will be erroneous. For reviews of cell mechanics and parameters affecting their interpretation see refs. ${ }^{[130-134]}$.

In order to ensure that accurate and meaningful values can be obtained from a given experiment, great care and consideration are required in order to determine the exact mechanical property, lengthscales, and timescales which are of interest in understanding a sample's behavior. Once these have been identified, experiments can then be carefully planned to extract the relevant parameters with adequate consideration to limitations in data collection and the application of contact mechanics models. Here, we present a clear set of guidelines for quantitative data collection and analysis. The reader is also encouraged to review previous guidance provided in the literature. ${ }^{[29,33-35,68,69,135-137]}$.

\subsubsection{Indentation Depth}

Since most contact mechanics models depend on an assumption of anisotropy, it is important to choose an indentation depth which is small $(<10 \%)$ compared to the thickness of 
the sample such that the mechanical influence of the substrate is minimal. ${ }^{[138]}$ Failure to adhere to this condition may require the application of thin film models ${ }^{[107,135,139]}$ to correct for the influence of the substrate, thereby complicating the analysis and interpretation of data. For thick samples the indentation depth should be smaller than the critical parameter of the indenter geometry (i.e., tip height for a conical indenter or the sphere radius for a spherical intender). Harris and Charras used confocal microscopy to characterize the tip-sample contact area as a function of indentation depth; whereas the contact was found to be spherical using spherical tips, leading to correct values, pyramidal tips only had pyramidal contacts for small indentations and often the lever itself came into contact with the cell, leading to an underestimation of the modulus. ${ }^{[83]}$ They also identified that any offset of the tip position from the end of the cantilever and the angle of inclination of the lever relative to the surface will limit the maximum accessible indentation depth. The above factors limit the maximum useful indentation depth for a given sample. By analyzing the elastic modus for a sample as a function of indentation depth, a region can generally be identified between these limits where the values are constant. ${ }^{[138]}$

\subsubsection{Contact Size}

Contact area directly determines the range of moduli that can be accessed for a given cantilever spring constant, $k$. Microfabricated cantilevers generally contain an asymmetrical pyramidal tip which enables high resolution spatial mapping but when indenting biological samples there is a risk of sample damage (e.g., cell membrane rupture) or exceeding the linear elastic limit, which is generally interpreted as a strain of $20 \% .{ }^{[135]}$ In addition, the presence of cytoskeletal elements in cells often results in the measurement of local moduli that are orders of magnitude higher $(\sim \mathrm{GPa})$ than the surrounding cytoplasm, ${ }^{[127,140]}$ thereby complicating statistical interpretation of data. In such cases statistical methods such as outlier rejection ${ }^{[127]}$ and principal component analysis ${ }^{[141]}$ may need to be applied.

For complex hierarchical biological systems such as cells it may be beneficial to choose a sphere geometry for the interaction, as it allows for both the averaging of the mechanical 
response over a larger contact area but also allows for the modulus to be determined with smaller indentation depths and higher spring constants. Caution needs to be exercised when using this approach to ensure 1) alignment of the sphere with the cell by combining AFM with optical techniques and 2) use of geometry where $R \gg$ cell or where $R \ll<$ cell but in the case of sphere indentation of cells there is often a case where $R \sim$ cell size which can complicate interpretation of data. Whilst spheres are often chosen to average areas of the sample and/or to enable the measurement of mechanical properties of samples with low moduli, the complications associated with large adhesions may impede the interpretation of data. Furthermore, the use of spheres larger than the width of the cantilever can cause changes to the measured deflection during indentation and require additional corrections to be applied. ${ }^{[142]}$ Some authors have also employed flat punch geometries for AFM nanoindentation that simplify data analysis by having a constant contact area during indentation. However, such geometries may cause damage to the sample due to the concentration of forces at the edges of the indenter and care must be taken to ensure a parallel contact with the sample, which is difficult in AFM since the cantilever is inclined. ${ }^{[112,143]}$

\subsubsection{Spring Constant}

The core principle of optimizing indentation data is matching the sample stiffness to the spring constant for a given indentation depth; when the correct spring constant is selected, there should be a 1:1 ratio between indentation depth and deflection. The use of cantilevers that are too soft results in the measurement being dominated by the bending of the cantilever whilst cantilevers that are too stiff will not adequately deflect when indenting the sample. In order to determine an appropriate spring constant for a given sample, the contact geometry, estimated indentation depth, and an estimate of the sample stiffness must be known. By taking the partial derivative of 2.1 and 2.2 with respect to indentation, the sample stiffness, $\partial F / \partial \delta$, can be obtained from 


$$
\frac{\partial F}{\partial \delta}=-\frac{2 E \sqrt{R \delta}}{v^{2}-1}
$$

for a sphere, and

$$
\frac{\partial F}{\partial \delta}=\frac{4 E \delta \tan \alpha}{\pi\left(1-v^{2}\right)}
$$

for a cone. Plotting $\partial F / \partial \delta$ as a function of $\delta$ yields a plot where an appropriate spring constant can be chosen based on geometry and $\delta$ (Figure 6).

The maximum indentation depth is determined by both sample thickness and indenter geometry as outlined above. There is an additional constraint to ensure that the cantilever response is Hookean whereby the deflection must be kept within the linear small deflection limit (< thickness of the cantilever). ${ }^{[144]}$ Since the cantilever stiffness is matched to the sample stiffness at the maximum indentation depth, $\delta_{\max }$, the maximum deflection of the lever will be $\sim \delta_{\text {max }}$. Therefore, the voltage detected during indentation will be

$$
V_{\max } \approx \frac{\sim \delta_{\max }}{\operatorname{InvOLS}}
$$

where $V_{\text {max }}$ should be kept within the linear range of the position sensing photodiode (generally $0 \pm 50 \%$ of full range) and InvOLS is the inverse optical lever sensitivity.

The minimum indentation depth will depend on sample structure considerations, the minimum detectable deflection, and the cantilever deflection noise. In most commercial AFM systems, the noise in the detection system will be the limiting value. The cantilever also has a deflection noise due to its thermal motion, which is proportional to temperature and inversely proportional to the spring constant. ${ }^{[145]}$

$$
N_{\text {Defl }}=\sqrt{\frac{4 k_{B} T}{3 k}}
$$

The indentation depth should be such that the maximum deflection is an order of magnitude greater than the maximum of the detection and deflection noise (whichever is greater). Softer cantilevers will require a greater indentation depth at the cost of increased deflection noise. 


\subsubsection{Indentation Rate}

The loading rate of the indentation is dependent on the piezo extension velocity during the force-distance curve. Most commercial AFM systems specify this velocity indirectly as the number of force curves per second (force rate $(\mathrm{Hz})$ ) which can be converted to a velocity by taking the total $\mathrm{Z}$ travel (approach + retract distance) multiplied by the force rate. For a given experiment there is a tradeoff between velocity, acquisition time, drift, sample temporal stability, ${ }^{[146]}$ and viscoelasticity ${ }^{[91,119-121]}$ of the sample. Whilst the previous discussion has presented principles that apply equally to ambient and liquid environments we now focus on the influence of cantilever hydrodynamics which can be significant in liquid environments. ${ }^{[136]}$

The influence of hydrodynamics on a cantilever in motion is proportional to the velocity and indenter size and inversely proportional to the spring constant. ${ }^{[147]}$ For a spherical indenter approaching a planar surface, the hydrodynamic force acting on the cantilever will be

$$
F_{H y d}=\frac{6 \pi \eta R^{2} \mathrm{v}}{D} \quad(D \ll R)
$$

where $D$ is the tip-surface separation, $\eta$ is viscosity, and $\mathrm{v}$ is the tip-sample velocity. Typical rates, $\mathrm{v}$, for a conical tip indenting a biological surface are between 0.1 and $10 \mu \mathrm{m} / \mathrm{s}^{[31]}$ with lower velocities required for spheres due to the larger hydrodynamic drag force. ${ }^{[147]}$

\subsubsection{Mapping of Mechanical Properties}

There are several commercial AFM implementations where force curves are spatially mapped across a sample in order to generate maps of mechanical properties (discussed in more detail in Section 5). These include Force Volume (F-V), Fast Force Mapping, FastForceVolume ${ }^{\mathrm{TM}}, \mathrm{QI}^{\mathrm{TM}}$, QI-Advanced ${ }^{\mathrm{TM}}$, Peak Force $\mathrm{QMN}^{\mathrm{TM}}$ where each method differs in the way the data is acquired and analyzed. Despite some of these methods offering faster data collection and spatial XY translation during data collection, all of the core principles discussed thus far remain equally applicable. When mapping, there should be some consideration of avoiding overlapping indents such that each indent accesses a new area of the sample. As such, 
a general rule of thumb is that each indent should be 5-10 times the contact radius away from the previous location so that each measurement can be considered independent. This restricts the utility of high resolution mapping to small indentations, which may not reveal the true stiffness of complex hierarchical materials and may also limit cantilever choice. The circular contact area for an indentation of given depth can be determined using the following ${ }^{[148]}$ :

$$
A_{\text {Sphere }}^{\text {Ind }}=\pi\left(2 R \delta-\delta^{2}\right)
$$

for a sphere and

$$
A_{\text {Cone }}^{\text {Ind }}=\pi \delta^{2} \tan ^{2} \alpha
$$

for a cone geometry. For large spheres this means that there may only be a single unique indentation location per cell where the contact area is free from influence of other indentations.

\subsubsection{AFM Indentation Data Analysis}

In order to extract accurate mechanical properties from force-distance curves, the sensitivity and stiffness of the cantilever must first be calibrated. Since the deflection in AFM is recorded as a voltage on a position sensitive photodetector there are two calibration parameters required; firstly to convert the bending of the cantilever from voltage to deflection, known as the InvOLS and secondly the spring constant, which allows the deflection to be converted to force through Hooke's law. InvOLS can be determined by measuring the slope of a force-distance curve against a hard substrate (e.g., glass or sapphire, making some assumptions about the nature of the contact mechanics) and relies on accurate calibration of the $\mathrm{Z}$ piezo of the AFM. These values can then be used in conjunction with the thermal noise spectrum of a cantilever (vibration of the cantilever due to thermal energy) recorded far from the sample surface in order to determine $k$ using the thermal method. ${ }^{[145]}$ One main disadvantage of this approach is that the measurement of InvOLS can often result in tip damage, causing a loss in resolution and poorly defined indenter geometry. ${ }^{[149]}$ The thermal method also requires the use of the kappa factor, $\kappa$, to account for a difference in the bending shape of a cantilever for an end-loaded cantilever (i.e., the case when measuring InvOLS, indenting or scanning in 
contact mode) versus a cantilever with a free end (i.e., the case when measuring thermal spectra or scanning in dynamic modes). This is generally taken to be $\kappa=1.09$ (where InvOLS Dynamic $=$ $\kappa$ InvOLS $\left._{\text {Static }}\right)^{[150]}$ but significant corrections may be required for finite optical spot size and position effects ${ }^{[151]}$ as well as cantilever geometry. ${ }^{[152]}$ An alternative approach is to use the thermal noise spectrum of the cantilever in conjunction with the Sader method (originally developed for rectangular cantilevers ${ }^{[153]}$ but later extended to cantilevers of arbitrary shape ${ }^{[154]}$ ) to obtain the spring constant directly and then derive the InvOLS ${ }_{\text {Dynamic }}$ value. ${ }^{[149]}$ Using the Sader method requires the use of $\kappa$ to convert InvOLS $S_{\text {Dynamic }}$ to InvOLS $S_{\text {Static }}$ to allow for calibration of indentation measurements. Both the InvOLS value and $k$ should be measured for every experiment as minor changes in laser spot position can cause large changes in the determination of these values.

Generally, the analysis of the mechanical properties of a material by AFM requires the determination of the force vs. $\delta$ profile for a given force curve. This is constructed by subtracting the measured deflection of the cantilever from the known $\mathrm{Z}$ position. This allows for routine determination of the POC for a stiff cantilever interacting with a stiff sample but for soft samples, where the sample can deform due to long-range forces before tip-sample contact occurs, this transition is poorly defined leading to an unknown $\delta$ and large errors in any derived mechanical properties. ${ }^{[155]}$ Many strategies have been employed in the literature for POC determination including visual inspection, ${ }^{[156]}$ model fitting, ${ }^{[155]}$ extrapolation of the first derivative, ${ }^{[122,156]}$ and Bayesian analysis. ${ }^{[157]}$ For a brief review of POC determination methods see ref. ${ }^{[157]}$. Harris and Charras demonstrated that AFM combined with confocal microscopy can be used to verify the POC. ${ }^{[83]}$ The consequences of inaccurately determining the POC is discussed in detail in ref. ${ }^{[155]}$.

Consequently, methods have been developed to allow the determination of a sample's elastic modulus without needing to determine the POC. A-Hassan initially developed a protocol 
which enabled the determination of sample modulus by a comparison against a known reference sample. ${ }^{[158]}$ Later techniques involving the linearization of the Hertz and Sneddon equations have since become prevalent where Equations 1 and 2 become ${ }^{[159]}$

and

$$
\left(f_{\text {sphere }}\right)^{2 / 3}=\left(\frac{4}{3} \frac{E}{1-v^{2}} \sqrt{R}\right)^{2 / 3} \delta
$$

$$
\left(f_{\text {cone } e}\right)^{1 / 2}=\left(\frac{2}{\pi} \frac{E}{1-v^{2}} \tan \alpha\right)^{1 / 2} \delta
$$

Measuring the slope of $\left(f_{\text {sphere }}\right)^{2 / 3}$ or $\left(f_{\text {cone }}\right)^{1 / 2}$ vs. $\delta$ then allows $E$ to be determined using the following relationships ${ }^{[159]}$

$$
E=\frac{3}{4} \operatorname{slope}^{3 / 2} \frac{1-v^{2}}{\sqrt{R}}
$$

and

$$
E=\frac{\pi}{2} \operatorname{slope}^{2} \frac{1-v^{2}}{\tan \alpha}
$$

Here, the remaining terms are the geometric parameters and the Poisson's ratio. For the geometric parameters, relative or absolute methods may be used to determine the critical parameters. For the relative method, a calibrated cantilever is indented into a material with known properties and then the contact size is used as a free parameter. ${ }^{[156]}$ The drawback of this technique is that it assumes that the same contact mechanics model applies for the unknown sample and the geometric parameters are only valid at the same indentation depth, which may be difficult to achieve on an unknown sample given the other requirements for parameter selection. Absolute methods use SEM or blind tip reconstruction ${ }^{[160]}$ to determine the critical parameters.

For microfabricated cantilevers with an asymmetric pyramidal tip, $\alpha$ can be determined by equating the cross sectional area of a tip at a given height with an equivalent cone. For the example of an asymmetric pyramid with differing front, back and side angles (Figure 7) the equivalent cone angle can be calculated for large indentations using 


$$
\alpha=\tan ^{-1}\left(\sqrt{\frac{2}{\pi} \sec S A(\tan \mathrm{BA}+\tan \mathrm{FA}) \tan \mathrm{SA}}\right)
$$

The determination of an appropriate Poisson's ratio for biological samples remains a topic of contention in the literature with most AFM indentation studies relying on a value of 0.5 , which assumes that the sample is incompressible. A few studies have attempted to measure or model the Poisson's ratio of a cell, yielding values between 0.3 and $0.5 .^{[161-165]}$ Harris and Charras used AFM combined with confocal microscopy to show that cells bulge outward under indentation and are incompressible. ${ }^{[83]}$ Nijenhuis et al. recently combined two independent measurements of mechanical properties, AFM and scanning acoustic microscopy, to directly determine the Poisson ratio of mouse fibroblasts to be close to $0.5 .^{[165]}$ The impact of choice of Poisson's ratio on the modulus measured is generally within the uncertainty of an AFM indentation experiment. ${ }^{[166]}$ Alternatively the reduced Young's modulus, $E_{r}$, may be reported where

$$
\frac{1}{E_{r}}=\frac{1-v_{s}^{2}}{E_{s}}+\frac{1-v_{i}^{2}}{E_{i}}
$$

and $s$ and $i$ subscripts denote the sample and indenter, respectively.

Automated analysis routines have been implemented using a range of the techniques discussed above to allow for rapid throughput of analysis both offline ${ }^{[103,156,157,159,167]}$ and more recently online. ${ }^{[168]}$ In order to accurately assess the validity of values obtained from any AFM indentation based technique it is important to understand the limits of calibration accuracy, model assumptions, and the impact of choice of experimental conditions.

\section{AFM Studies of Cell Mechanotransduction}

Cells are often complex, heterogeneous, and relatively soft materials. Their cytoplasm contains a wide range of proteins of all sizes, networks of filaments, and organelles, all in constant movement. Cellular functions, such as motility, secretions, mitosis, and apoptosis involve a constant reorganization of internal cellular structures, creating variations in their 
internal pre-stress pressure. Cells are also constantly subject to external variable loads and understanding their adaptive response to these external forces is fundamental. ${ }^{[169,170]}$ It is well described that cells use mechanosensors that activate internal signaling pathways, leading to cytoskeletal reorganization and other activation pathways. This area of research called 'mechanotransduction' ${ }^{[14,171]}$ offers insight on how cells react at the molecular level to forces applied externally on their membranes and how cells interact with their environment. An extended review of the mechanisms of transduction can be found in ref. ${ }^{[132]}$.

Numerous pathologies are linked to changes in the mechanical characteristics of some cells: For example, sickle cell anemia is related to a change in the internal structure of red blood cells (RBCs), which lose their ability to deform; smooth muscle cells in the lung and their ability to contract are a key player in the pathology of asthma; an early sign of arthritis is a softening of the articular cartilage. ${ }^{[172]} \mathrm{A}$ vast number of publications show that the physiopathology of cancers involve a change in the viscoelastic properties of cells: The more aggressive types of cancer correspond to the less viscoelastic cells. ${ }^{[6,173-175]}$ The hope is that continuing research in this area will further our understanding and lead to new treatments.

A range of techniques are used to understand mechanotransduction. Classic methods in biochemistry aim to understand, in vitro, the molecular cascade of the mechanotransduction. Techniques based on the measurement of mechanical properties include particle tracking microrheology, ${ }^{[176]}$ micropipette aspiration, ${ }^{[177,178]}$ optical tweezers, ${ }^{[179]}$ traction microscopy, ${ }^{[180,181]}$ and magnetic tweezers ${ }^{[182,183]}$ with AFM becoming dominant. ${ }^{[119]}$ AFM offers numerous advantages; it can be used on live cells under physiological conditions with remarkably high spatial resolution, can detect or apply local forces as low as a few $\mathrm{pN}$ and as high as a few $\mathrm{nN}$, and can generate topographical images of the surface of cells without causing damage. ${ }^{[184]}$

Mechanical experiments performed by AFM to study cell mechanics can be divided into three categories: 
1. Measuring the viscoelastic properties of cells by using the AFM cantilever as an indenter and measuring the Young's modulus of the cell.

2. Measuring the adhesion of cells to different substrate properties (e.g., thickness, stiffness, ligand binding density, stretching). These types of studies often involve attaching a cell to a cantilever, allowing it to attach to the substrate of interest and measuring the force required to detach it from the substrate surface. Other studies assess the behavior of cells (e.g., motility, proliferation) in response to changes in the properties of the substrate.

3. Studying the molecules involved in the attachment of the cells on their substrate and in the molecular cascade of mechanotransduction.

In this section we describe how researchers are using AFM to study cell mechanics and present an overview of the main results.

\subsection{General Guidelines on how to Study Cells with AFM}

Prior to performing force measurements on cells, researchers may want to image them to measure their morphology. In general, it is easier to image fixed cells since they are stiffer, ${ }^{[96]}$ but the procedures are the same. Care must be taken to be gentle with the AFM probe to avoid damaging the cells or detaching the cells from their substrates (e.g., Petri dish, glass slide). Cells can be imaged in either contact mode or dynamic modes. In general, imaging is performed slowly, to minimize feedback errors that can damage the membranes $(0.2-0.3 \mathrm{~Hz}){ }^{[185]}$ Examples of contact mode and amplitude modulation mode imaging of live cells in liquid are shown in Figure 8, demonstrating an ability to visualize the underlying cytoskeleton.

One of the biggest challenges to performing nanomechanical measurements of cells by AFM is to grow cells that are well adhered to a flat substrate. If the cells are not adherent enough, they may be removed by the AFM tip during imaging. Some typical cell culture procedures may be utilized, such as promoting cell adhesion with poly-lysine (poly-L-lysine or poly-D-lysine), collagen, laminin or fibronectin coatings. ${ }^{[186]}$ Immobilization techniques with 
poly-lysine or other molecules ${ }^{[187]}$ have proven to be indispensable for imaging RBCs and bacteria. ${ }^{[188-192]}$ Some authors have had success growing bacteria directly on a glass slide to promote the attachment of the cells on their own biofilm. ${ }^{[193]}$ Others have used microfabricated wells to trap individual bacterium ${ }^{[194]}$ and other nonadherent cells. ${ }^{[195,196]}$ AFM has been widely used to study molecular interactions and elasticity of bacteria ${ }^{[67,192,197-201]}$ and in some cases, high resolution images of live bacterium membranes have been obtained. ${ }^{[187,188]}$ Finally, some authors are using cellulose filter pores to immobilize yeast cells. ${ }^{\text {[202-204] }}$

For contact mode imaging and force curve investigations on cells with AFM, low spring constant cantilevers are used (typical values are 0.02 to $0.1 \mathrm{~N} / \mathrm{m}$ ) to avoid relatively high vertical forces. Dynamic modes can be used to image cells with small forces using higher spring constants. ${ }^{[205,206]}$ To ensure ideal conditions, live cell experiments should be performed in a controlled environment. In practice, users are often able to work at $37^{\circ} \mathrm{C}$. Less often, because of hardware limitations, experiments are conducted with a flow of $\mathrm{CO}_{2}$ to maintain a correct $\mathrm{pH}$ in the cell culture medium.

\subsection{Measuring Young's Modulus of Cells}

Under physiological conditions, most cells are intrinsically viscoelastic, with a combination of both elastic and time-dependent responses to deformation. The majority of AFM publications relating to cell mechanics attempt to determine a value for the cell elastic modulus, which ranges from a few hundred of $\mathrm{Pa}$ to tens of $\mathrm{kPa}$. Tao and Lindsay were the first to quantify local elastic properties of cells using AFM. ${ }^{[207]}$ Since then, the number of publications using these types of measurements has been constantly expanding (see Figure 2), and involves a large variety of cells including: human epithelial cells, ${ }^{[208]}$ stem cell-derived cardiomyocytes, ${ }^{[209]}$ mesenchymal stem cells, ${ }^{[170]}$ neurons, ${ }^{[210]}$ chondrocytes, ${ }^{[211]}$ and fibroblasts. ${ }^{[89,91,212]}$ A typical set of data obtained on live cells is shown in Figure 9.

Since the mechanical properties of cells are determined largely by the cell membrane and the internal cytoskeleton, significant efforts are aimed at understanding the role of each of 
these components and their interplay. An understanding of the importance of actin filaments has proved to be essential in this regard. These are semi-flexible structures, with a persistence length of about $20 \mu \mathrm{m},{ }^{[116]}$ capable of rapidly growing to enable cell motion. These filaments can sustain mechanical stress by forming a $200 \mathrm{~nm}$-thick mesh below the apical plasma membrane of mammalian cells (see Figure 8). They are also partly responsible for the anchorage of cells to the ECM. Authors are often interested in looking at actin filaments and more generally at cytoskeleton structures with AFM. In a pioneering work, Henderson et al. used AFM to study the dynamic behavior of the cytoskeleton of live glial cells. ${ }^{[213]}$ More recently, Pesen and Hoh used AFM to describe in detail the network of filaments forming the cytoskeleton. ${ }^{[214]}$ It has been shown that the stress fibers observed with AFM are mainly F-actin fibers. ${ }^{[170]}$ An interesting approach to obtain more information about the relationship between the viscoelastic properties of cells and the cytoskeleton is to look at the effect of anticytoskeletal drugs (e.g., cytochalasin B, colchicine, taxol) on the Young's modulus of cells, ${ }^{[89]}$ and even coupling this type of measurement with a direct observation of the re-organization of the cytoskeletal fibers in response to spatial confinement. ${ }^{[86]}$

Eloquent examples to illustrate the importance of studying cell mechanics come from blood cells. In vivo, many cells need to travel inside and even migrate across capillaries sometimes smaller in diameter than their own diameters requiring cells to deform and change shape to a great extent. RBCs are a good example of this capacity of cells to deform. They are very soft cells (Young's modulus of about $0.15 \mathrm{kPa})^{[215]}$ but any increase of their stiffness is a key indicator of many diseases associated with anemia. ${ }^{[216]}$ Many studies have used AFM to understand how a modification in the structure of hemoglobin inside RBCs leads to a change in the structure of the membrane (decrease of rugosity) and an increase of the Young's modulus and the viscosity, from healthy to diseased cells. ${ }^{[190,215]}$

Metastatic cells, which are responsible for the propagation of cancer cells, are another type of cell required to travel and pass through capillaries with small diameters. These cells 
exhibit a re-organization of cystoskeletal proteins and their contraction, stretch ability, deformability, and viscoelastic properties are all modified. ${ }^{[217]}$ Alterations of the actin filaments appear to be the main factor responsible for these changes in cancer cells. ${ }^{[218]}$ Many publications using AFM quantitative data show that cancer cells are softer and more fluid-like compared to non-malignant cells. ${ }^{[219,220]}$ Therefore, AFM may be used as a diagnostic tool for the identification of cancerous cells by measuring the cell stiffness and comparing values to benign cells. ${ }^{[221-223]}$ In addition to the measurement of Young's modulus of highly aggressive metastatic cells, AFM has been used to study the role of the nucleus in cell stiffness, revealing that the nuclear mechanical properties of two lines of cancer cells correlated well with their metastatic efficiency. ${ }^{[223]}$

\subsection{Cell-Cell Adhesion and Cell-ECM Adhesion}

Studying cell mechanics at the molecular level includes measuring the molecular interaction between a ligand and a receptor. After the pioneering work of Florin et al. measuring the binding energy of avidin and biotin, ${ }^{[224]}$ some authors have repeated this type of experiment. ${ }^{[225,226]}$ However, coating a tip with a ligand and maintaining its functionality is challenging since the attachment needs to be oriented to expose the binding sites of the molecule at the tip apex ${ }^{[227]}$ and subsequently, most authors use polyethylene glycol linkers ${ }^{[46,228]}$ in order to provide freedom for the ligand and receptor to interact. The number of molecules attached to the tip is also difficult to control and quantify.

More successful has been the study of cell adhesion to other cells. For example, lymphocytes located inside the blood stream are important cells involved in the body's defense that need to deform significantly in order to cross capillaries. This transendothelial migration is of particular importance in inflammatory responses and immune reactions. This process first involves the lymphocyte adhering to endothelial cells via specific molecules and junctions at the surface of the cells. AFM has been used to assess the attachment and immobilization of lymphocytes at the molecular level with a high spatial resolution. Jaczewska et al. have attached 
a lymphocyte (Jurkat cell) to an AFM cantilever via ConA ligands to measure the de-adhesion of a single lymphocyte on endothelial cells (HUVEC). ${ }^{[229]}$ The work of de-adhesion was found to be $1.4 \times 10^{-6} \mathrm{~J}$ at the center of the endothelial cell and about $1.6 \times 10^{-6} \mathrm{~J}$ around the junction. The authors also coated the AFM tip with an endothelial receptor (JAM-A) capable of binding to the lymphocyte receptor LFA-1. They used this coated tip to localize the position of adhesion spots on endothelial cells with a force of about 50 to $100 \mathrm{pN}$. This work is illustrative of the remarkable range of experiments possible with AFM; not only were the authors able to control the environment around the cells (e.g., temperature), they were also able to measure the effects of the addition of molecules inside the medium, such as blocking antibodies, in real time. Such single cell force spectroscopy measurements have also been successfully applied to study other cell types. ${ }^{[82,230-234]}$

\section{Nanomechanical Properties of Natural and Engineered Biomaterials}

The motivations for probing the nanomechanical properties of biomaterials are diverse. For instance, from a biomimicry viewpoint, the optimization of lubrication in hydrogels benefits from the measurement and understanding of the ultralow friction properties of cartilage under load. ${ }^{[41,42,235-238]}$ In addition, natural nano- to micron-sized biomaterials are used in various applications including stimuli responsive nanocomposites, ${ }^{[239]}$ where understanding the mechanical properties of, e.g., individual cellulose microfibrils ${ }^{[240]}$ is required. Furthermore, many biomaterials, including collagenous tissues such as bone and teeth, exhibit a complex hierarchical micro- to nano-structure, which often comprise dissimilar materials. AFM provides the possibility of probing the mechanical properties of mineral (i.e., apatite in bone and teeth) and protein (i.e., collagen) phases separately.

In measurements of bone, Tao et al. used AFM to quantify variations in moduli across a section of hydrated cow tibia, reporting variations between osteonal and intersitial lamellae with $50 \mathrm{~nm}$ resolution. ${ }^{[207]}$ Thompson et al. used a combination of indentation and pulling experiments to show that the toughness of bone is related to the energy dissipation of collagen 
sacrificial bonds. ${ }^{[241]}$ In measurements of teeth, Balooch et al. reported that AFM indentation measurements of hydrated demineralized dentin demonstrated purely viscoelsastic behavior, which disappeared upon desiccation leading to a more than 4-fold increase in modulus ${ }^{[242]}$ Fong et al. probed modulus and hardness across the dentin-enamel junction in sectioned human incisor teeth showing a transition from $\sim 4.8 \mathrm{GPa}$ in enamel to $\sim 0.80 \mathrm{GPa}$ in dentin and allowing the identification of the dentin-enamel junction as a 15-25 micron thick composite, which acts to inhibit crack formation. ${ }^{[243]}$ Habelitz et al. used an AFM with an indenter system having a cube corner indenter ( $\sim 20 \mathrm{~nm}$ radius) for indentation and scanning to reveal the anisotropy in modulus and hardness in human molar tooth enamel resulting from the microstructural texture arising from presence of rod-shaped apatite crystals. ${ }^{[166]}$

Cartilage, despite being composed primarily of a hydrated network of collagen fibrils, is a complex composite material, reported to have different bulk and nanoscale mechanical properties. ${ }^{[74]}$ Stolz et al. compared AFM indentation measurements recorded using $\sim 2.5 \mu \mathrm{m}$ radius spherical probes and sharp pyramidal AFM tips of radius $\sim 20 \mathrm{~nm}$ to reveal 100 -fold lower modulus for nanoscale measurements. ${ }^{[74]}$ In contrast the more homogeneous agarose gels prepared for comparison showed no lengthscale dependence. ${ }^{[74]}$ In addition, enzymatic digestion of proteoglycans in the articular cartilage resulted in an increase in stiffness at the nanometer but not micrometer scale. ${ }^{[74]} \mathrm{AFM}$ indentation measurements have also been performed on the extracellular and pericellular matrices of cartilage, ${ }^{[244-247]}$ and other tissues, including the sclera of the eye, ${ }^{[248,249]}$ and tendon. ${ }^{[250]}$

Individual collagen type I fibrils have also been investigated extensively using AFM nanomechanical measurements. In 2006, Heim et al. determined the modulus of native collagen fibrils harvested from sea cucumber dermis to be 1-2 GPa in air and reported that the value was relatively constant for fibrils having a diameter of greater than $\sim 50 \mathrm{~nm} .{ }^{[251]}$ In 2007 , Wenger et al. reported on the mechanical properties of native rat tail tendon collagen fibrils recorded in air, noting a variation in modulus values from 3.7-11.5 GPa attributed to, among other factors, 
the degree of dehydration. ${ }^{[252]}$ Grant et al. reported that the modulus of reconstituted bovine Achilles tendon collagen was $1.9 \pm 0.5 \mathrm{GPa}$ in air and $1.2 \pm 0.1 \mathrm{MPa}$ in sodium phosphate buffer $^{[253]}$ and that this modulus could be increased up to $200 \mathrm{MPa}$ in liquid by adjusting the $\mathrm{pH}$ and solvent. ${ }^{[254]}$ These results pertaining to collagen fibrils are generally valid under the assumption that the fibrils are isotropic, ${ }^{[252]}$ however, the structural arrangement of collagen type I molecules in a fibril leads to an anisotropic material, ${ }^{[255]}$ as shown experimentally through AFM nanoindentation measurements by Minary-Jolandan and Yu in 2009. ${ }^{[256]}$ The overlap and gap regions, which give rise to the well-known $\sim 67 \mathrm{~nm}$ D-periodicity, ${ }^{[255]}$ were reported to have moduli values in air of $\sim 2.2 \mathrm{GPa}$ and $\sim 1.2 \mathrm{GPa}$, respectively (Figure 10), and this experimentally-observed mechanical heterogeneity was corroborated by molecular dynamics simulations. $^{[257]}$

Perhaps the main driving force, however, for probing the nanomechanics of biomaterials by AFM relates to tissue engineering. As discussed in Section 1, ECM elasticity influences a range of cell properties (e.g., cell shape, adhesion, differentiation) ${ }^{[2-12]}$ and AFM measurements have been key to understanding the nanomechanical properties of cell microenvironments and characterizing the nanomechanical properties of biomaterials for tissue engineering applications. ${ }^{[139,258]}$ As reviewed above, AFM indentation measurements have been used to determine the modulus of cartilage ECM. ${ }^{[244]} \mathrm{AFM}$ has also been used to characterize meniscus $\mathrm{ECM},{ }^{[259,260]}$ sectioned arteries, ${ }^{[139,261]}$ including atherosclerotic plaques, ${ }^{[262,263]}$ human trabecular meshwork, ${ }^{[264]}$ with implications for glaucoma, corneal basement membrane, ${ }^{[265]}$ decellularized lung scaffolds, ${ }^{[266]}$ breast tissue, ${ }^{[267]}$ including mammary glands, ${ }^{[268]}$ and human dermis, ${ }^{[269]}$ among others. Goetz et al. demonstrated that caveolin-1 promotes tumor invasion through microenvironment stiffening, observing that the Young's modulus of wild type compared to caveolin-1 knock out mouse embryonic fibroblast-derived matrices was $40 \%$ larger and exhibited a larger standard deviation. ${ }^{[72]}$ 
Many recipes are available for the preparation of hydrogels with tunable mechanical properties $^{[31,270]}$ and microfluidics approaches exist for developing mechanical property gradients. ${ }^{[139,271]}$ An early foray into the use of AFM to probe the mechanical properties of hydrogels by Radmacher et al. in 1995 used AFM indentation measurements as a function of loading force extracted from force curves to determine solvent-dependent moduli of gelatin. ${ }^{[272]}$ Domke and Radmacher noted later that for films less than 1 micron thick the Hertz model no longer matched the experimental data due to the influence of the underlying glass slide. ${ }^{[273]}$ Rico et al. investigated the nanomechanical properties of $500 \mu \mathrm{m}$-thick agarose gels and epithelial cells using both blunted pyramidal and spherical tips, developing a contact model to determine viscoelastic properties of soft samples with tips conventionally used for imaging. ${ }^{[97]}$ They reported that the sharp ( $100 \mathrm{~nm}$ radius $)$ tip had the same force-indentation response for small indentations $(<300 \mathrm{~nm})$ as the spherical tips $(\sim 2.5 \mu \mathrm{m}$ radius $)$, whereas the modulus determined for deeper indentations was roughly twice as high for the pyramidal tips. ${ }^{[97]}$ Soofi et al. used AFM indentation to determine the elastic modulus of $1 \mathrm{~mm}$-thick Matrigel films, choosing the thickness in order to minimize the influence of the substrate. ${ }^{[274]}$ Nevertheless, Engler et al. reported that cell spreading on thin hydrogels (several $\mu \mathrm{m}$ ) was similar to spreading observed on thicker hydrogels and suggested that in both cases, the traction force generated by cells decays before reaching the substrate. ${ }^{[139]}$

In the same study, Engler et al. used AFM to determine the modulus of the smooth muscle cell-rich medial layer of sectioned arteries and created polyacrylamide gels of varying modulus, noting that smooth muscle cell spreading reached half its maximum value for polyacrylamide gels having moduli comparable to those of the arterial sections. ${ }^{[139]}$ As with the polyacrylamide gels, poly(L-lysine)-hyaluronic acid multilayer films showed a similar trend of increased spreading with increasing modulus. ${ }^{[139]}$ Guo et al. also prepared and tested polyacrylamide gels of varying stiffness to show that substrate rigidity influences cell migration and spreading of both immortal and primary cells with implications for tissue formation and 
maintenance. ${ }^{[258]}$ Similarly, Solon et al. prepared and tested polyacrylamide gels with AFM and showed that the substrate rigidity determines cell response. ${ }^{[123]}$

Ghosh et al. used AFM to determine the moduli of poly(ethylene glycol) diacrylate hydrogels with tunable stiffness and bioactivity as mimics of natural ECM and investigated the influence substrate rigidity on fibroblast migration and proliferation. ${ }^{[275]}$ The synthetic poly(ethylene glycol)-based hydrogels have also been investigated by other researchers. ${ }^{\text {[276-278] }}$ Photodegradable poly(ethylene glycol)-based hydrogels were introduced by Kloxin et al. allowing in situ modulation of the hydrogel elasticity. ${ }^{[276,277,279]}$ Similarly, Guvendiren and Burdick developed hyaluronic acid-based hydrogels with photo-assisted stiffening. ${ }^{\text {[280] }}$

Recent advances in applying AFM to the nanomechanical characterization of cells and biomaterials are presented in the next section.

\section{Recent Developments}

While most of the measurements discussed so far have been based primarily on local force-distance curve measurements, including force volume mapping wherein force-distance curves are recorded spatially and analyzed to generate maps of, e.g., elastic modulus, there is a general trend towards the use of scanning-based approaches for the simultaneous acquisition of surface topography and mechanical properties. Such modes are natural extensions of force modulation and amplitude modulation phase imaging, where quantification proves difficult since changes in phase can arise from multiple sources including adhesion, tip-sample contact area, and energy dissipation.

Following the approach of Anczykowski et al., ${ }^{[281]}$ Maguire et al. used amplitude modulation AFM to calculate and visualize the energy dissipated at locations coinciding with cytoskeletal components in mesenchymal stem cells. ${ }^{[206]}$ More recently, in 2012, Payam et al. proposed a model that explains phase contrast in amplitude modulation AFM, reporting that dissipation dominates the observed phase shift for soft and viscous materials. ${ }^{[282]}$ Frequency modulation AFM is generally more widely used than amplitude modulation AFM for 
quantitative measurements of dissipation. Kilpatrick et al. mapped energy dissipation in osteoblast cells using frequency modulation AFM, enabled by a routine to determine good initial estimates of the feedback parameters. ${ }^{[205]}$ Whereas in amplitude modulation, the tip intermittently taps the surface, in force modulation the sample is pushed into the tip with a controlled force during scanning. Thus, force modulation could be seen as a scanning contact mode version of force volume mapping. ${ }^{[283]}$ Present day examples of force modulation and advanced force volume modes take the form of, e.g., Peak Force QMNTM tapping mode and contact resonance $(\mathrm{CR})$ modes such as atomic force acoustic microscopy (AFAM) ${ }^{[284-286]}$ and ultrasonic atomic force microscopy (UAFM). ${ }^{[287]}$

Peak Force QMNTM is a tapping mode that allows for controlled force and indentation and the quantitative mapping of elasticity ${ }^{[288]}$ and has been used to probe the elastic modulus of heart valve leaflet stiffness ${ }^{[289]}$ and $\beta$-lactoglobulin ${ }^{[290]}$ and alpha synuclein ${ }^{[291]}$ amyloid fibrils. In CR modes, the sample is generally mounted onto an actuator, which excites cantilever vibrational modes, ${ }^{[292]}$ and was recently implemented using photothermal excitation. ${ }^{[293]} \mathrm{CR}$ modes have been generally used on relatively stiff materials, ${ }^{[285,286]}$ while still finding applications in biomaterials and polymers. ${ }^{[294]}$ AFAM has been used to map elasticity in antler, ${ }^{[295]}$ teeth, ${ }^{[296]}$ nacre, ${ }^{[297]}$ and recently smooth muscle cells, ${ }^{[298]}$ while UAFM has been used to image the elasticity of bacterial fragments. ${ }^{[299]}$ Complementary electromechanical information can be obtained about biological samples using piezoresponse force microscopy in combination with CR modes. ${ }^{[295,297]} \mathrm{CR}$ modes have been successful in mapping viscoelasticity and damping in a range of materials, ${ }^{[300-302]}$ with single, multifrequency, and multiharmonic approaches for CR imaging available. ${ }^{[303-308]}$

When mapping mechanical properties, the time for a given resolution (number of forcedistance curves) is dependent on the rate of acquisition (Figure 11). Ultimately, the upper limit of these techniques is due to mechanical limitations on the $\mathrm{Z}$ piezo motion (resonant frequency), the mechanical bandwidth of the cantilever, and the sampling rate, which determines the 
number of data points per force curve. Conversely, the time taken to map a given number of locations is inversely proportional to the ramp rate or cycle time. Recent advances in small cantilever technology combined with instrumentation developments are likely to see force volume-based techniques increase in speed. ${ }^{[212]}$

In addition to the possibility of mapping mechanical properties, subsurface imaging can be enabled by multiharmonic imaging modes and has been applied to imaging cells, ${ }^{[309,310]}$ nanoparticles in cells (Figure 12), ${ }^{[311]}$ and other materials. ${ }^{[312-315]}$ Multiharmonic approaches for measuring mechanical properties, often allow several materials properties, such as adhesion, stiffness, and dissipation to be captured simultaneously. ${ }^{[316,317]}$ Multifrequency and multiharmonic modes, where the excitation of the cantilever and/or detection of the dynamic response occurs at two or more frequencies, have become widely used in recent years. ${ }^{[318]}$ Various applications of bi-modal approaches, whereby two eigenmodes are simultaneously excited, have been used ${ }^{[319-323]}$ to image bio- and other materials, and novel approaches whereby the first cantilever resonance is operated in amplitude modulation mode and the second is operated in frequency modulation mode have been implemented. ${ }^{[322,324]}$ Excitation of the first resonance can lead to excitation of higher eigenmodes, due to nonlinear interactions, which have been used to map nanomechanical properties of cells ${ }^{[325,326]}$ and biological membranes. ${ }^{[327]}$

\section{Conclusion}

AFM-based nanomechanical measurements have become an indispensable tool for the characterization of biomaterials and will continue to be used to assess new natural and synthetic hydrogel materials as they are developed. This includes a wide range of integrated functional biomaterials for understanding cell mechanics ${ }^{[328]}$ and also $3 \mathrm{D}$ microtissues, ${ }^{[329]}$ paralleling trends in biomaterials research, as well as to understand disease. ${ }^{[264]}$ At the same time, AFMbased measurement techniques continue to be developed. The combination of AFM-based techniques for simultaneous mapping of complementary material properties and AFM with other scanning probe techniques, including scanning ion conductance microscopy ${ }^{[330,331]}$ and 
scanning acoustic microscopy are likely to continue being pursued. ${ }^{[165]}$ The continued integration $^{[13,48,80]}$ of optical, such as super resolution stimulated emission depletion, ${ }^{[332]}$ and atomic force microscopies for, e.g., mechanotransduction studies is an additional area for further development and the continued commercialization of small levers may lead to faster dynamic force mapping. ${ }^{[212]}$

\section{Acknowledgements}

This work was supported by Science Foundation Ireland under grant numbers SFI10/RFP/MTR2855 and SFI12/IA/1449 and NANOREMEDIES, which is funded under the Programme for Research in Third Level Institutions Cycle 5 and co-funded by the European Regional Development Fund.

\section{References}

[1] F. Rehfeldt, A. J. Engler, A. Eckhardt, F. Ahmed, D. E. Discher, Adv. Drug Deliv. Rev. 2007, 59, 1329.

[2] I. A. Janson, A. J. Putnam, J. Biomed. Mater. Res. - Part A 2014, 103, 1246.

[3] A. Engler, L. Bacakova, C. Newman, A. Hategan, M. Griffin, D. Discher, Biophys. J. 2004, 86, 617.

[4] A. J. Engler, S. Sen, H. L. Sweeney, D. E. Discher, Cell 2006, 126, 677.

[5] D. E. Discher, D. J. Mooney, P. W. Zandstra, Science 2009, 324, 1673.

[6] D. E. Discher, P. Janmey, Y.-L. Wang, Science 2005, 310, 1139.

[7] A. Buxboim, I. L. Ivanovska, D. E. Discher, J. Cell Sci. 2010, 123, 297.

[8] S. N. Kim, A. Jeibmann, K. Halama, H. T. Witte, M. Wälte, T. Matzat, H. Schillers, C. Faber, V. Senner, W. Paulus, C. Klämbt, Development 2014, 141, 3233.

[9] P. D. P. Dingal, D. E. Discher, Curr. Opin. Biotechnol. 2014, 28C, 46.

[10] N. Halliday, J. Tomasek, Exp. Cell Res. 1995, 217, 109.

[11] A. L. Zajac, D. E. Discher, Curr. Opin. Cell Biol. 2008, 20, 609.

[12] A. J. Engler, M. A. Griffin, S. Sen, C. G. Bönnemann, H. L. Sweeney, D. E. Discher, J. Cell Biol. 2004, 166, 877. 
[13] G. T. Charras, M. A. Horton, Biophys. J. 2002, 82, 2970.

[14] N. Wang, J. P. Butler, D. E. Ingber, Trends Cell Biol. 1993, 3, 257.

[15] M. E. Chicurel, C. S. Chen, D. E. Ingber, Curr. Opin. Cell Biol. 1998, 10, 232.

[16] P. Janmey, Physiol. Rev. 1998, 78, 763.

[17] S. Huang, D. E. Ingber, Nat. Cell Biol. 1999, 1, E131.

[18] C. Galbraith, M. Sheetz, Proc. Natl. Acad. Sci. U. S. A. 1997, 94, 9114.

[19] C. G. Galbraith, M. P. Sheetz, Curr. Opin. Cell Biol. 1998, 10, 566.

[20] D. Choquet, D. Felsenfeld, M. Sheetz, Cell 1997, 88, 39.

[21] Y. Wang, E. Botvinick, Y. Zhao, M. Berns, Nature 2005, 434, 772.

[22] H. J. Kong, T. R. Polte, E. Alsberg, D. J. Mooney, Proc. Natl. Acad. Sci. U. S. A. 2005, 102,4300 .

[23] G. Giannone, M. P. Sheetz, Trends Cell Biol. 2006, 16, 213.

[24] A. J. Keung, E. M. de Juan-Pardo, D. V Schaffer, S. Kumar, Stem Cells 2011, 29, 1886.

[25] Y. Kim, S. Kumar, Mol. Cancer Res. 2014, 12, 1416.

[26] G. Halder, S. Dupont, S. Piccolo, Nat. Rev. Mol. Cell Biol. 2012, 13, 591.

[27] F. Brandl, F. Sommer, A. Goepferich, Biomaterials 2007, 28, 134.

[28] D.-H. Kim, D. Wirtz, FASEB J. 2013, 27, 1351.

[29] T. Ludwig, R. Kirmse, K. Poole, U. S. Schwarz, Pflugers Arch. 2008, 456, 29.

[30] M. T. Frey, A. Engler, D. E. Discher, J. Lee, Y.-L. Wang, Methods Cell Biol. 2007, 83, 47.

[31] A. J. Engler, F. Rehfeldt, S. Sen, D. E. Discher, Methods Cell Biol. 2007, 83, 521.

[32] S. N. Magonov, D. H. Reneker, Annu. Rev. Mater. Sci. 1997, 27, 175.

[33] M. Radmacher, in Methods Cell Biology, Academic Press, San Diego 2007, pp. 34772.

[34] M. Radmacher, in Methods Cell Biology, Academic Press, San Diego 2002, pp. 67-90.

[35] M. Radmacher, IEEE Eng. Med. Biol. Mag. 1997, 16, 47. 
[36] H. Hansma, J. Hoh, Annu. Rev. Biophys. Biomol. Struct. 1994, 23, 115.

[37] H. G. Hansma, K. J. Kim, D. E. Laney, R. A. Garcia, M. Argaman, M. J. Allen, S. M. Parsons, J. Struct. Biol. 1997, 119, 99.

[38] H. Hansma, Annu. Rev. Phys. Chem. 2001, 52, 71.

[39] M. Benoit, D. Gabriel, G. Gerisch, H. E. Gaub, Nat. Cell Biol. 2000, 2, 313.

[40] E. L. Florin, M. Rief, H. Lehmann, M. Ludwig, C. Dornmair, V. T. Moy, H. E. Gaub, Biosens. Bioelectron. 1995, 10, 895.

[41] J. P. Gong, Soft Matter 2006, 2, 544.

[42] J. Klein, Science 2009, 323, 47.

[43] B. J. Rodriguez, S. V Kalinin, Kelvin Probe Force Microscopy, Springer Berlin Heidelberg, Berlin, Heidelberg, 2012.

[44] W. Liu, L. M. Jawerth, E. A. Sparks, M. R. Falvo, R. R. Hantgan, R. Superfine, S. T. Lord, M. Guthold, Science 2006, 313, 634.

[45] L. Kreplak, H. Bär, J. F. Leterrier, H. Herrmann, U. Aebi, J. Mol. Biol. 2005, 354, 569.

[46] P. Hinterdorfer, Y. F. Dufrêne, Nat. Methods 2006, 3, 347.

[47] I. Obataya, C. Nakamura, S. Han, N. Nakamura, J. Miyake, Nano Lett. 2005, 5, 27.

[48] M. P. Stewart, J. Helenius, Y. Toyoda, S. P. Ramanathan, D. J. Muller, A. A. Hyman, Nature 2011, 469, 226.

[49] M. P. Stewart, Y. Toyoda, A. A. Hyman, D. J. Müller, Nat. Protoc. 2012, 7, 143.

[50] Y. Toyoda, M. P. Stewart, A. A. Hyman, D. J. Müller, Jpn. J. Appl. Phys. 2011, 50, 08LA01.

[51] C. Leung, A. Bestembayeva, R. Thorogate, Nano Lett. 2012, 12, 3846.

[52] S. Ido, K. Kimura, N. Oyabu, K. Kobayashi, M. Tsukada, K. Matsushige, H. Yamada, ACS Nano 2013, 7, 1817.

[53] N. Kodera, D. Yamamoto, R. Ishikawa, T. Ando, Nature 2010, 468, 72.

[54] G. Lee, D. Kidwell, R. Colton, Langmuir 1994, 2, 354.

[55] G. U. Lee, L. A. Chrisey, R. J. Colton, Science 1994, 266, 771.

[56] C. Yuan, A. Chen, P. Kolb, V. T. Moy, Biochemistry 2000, 39, 10219.

[57] J. Fritz, A. G. Katopodis, F. Kolbinger, D. Anselmetti, Proc. Natl. Acad. Sci. U. S. A. 1998, 95, 12283. 
[58] T. E. Fisher, P. E. Marszalek, J. M. Fernandez, Nat. Struct. Biol. 2000, 7, 719.

[59] J. Zlatanova, S. M. Lindsay, S. H. Leuba, Prog. Biophys. Mol. Biol. 2000, 74, 37.

[60] M. Rief, M. Gautel, F. Oesterhelt, J. M. Fernandez, H. E. Gaub, Science 1997, 276, 1109.

[61] M. Rief, M. Gautel, A. Schemmel, H. E. Gaub, Biophys. J. 1998, 75, 3008.

[62] M. Rief, J. Pascual, M. Saraste, H. E. Gaub, J. Mol. Biol. 1999, 286, 553.

[63] A. S. Mostaert, M. J. Higgins, T. Fukuma, F. Rindi, S. P. Jarvis, J. Biol. Phys. 2006, $32,393$.

[64] F. Li, S. D. Redick, H. P. Erickson, V. T. Moy, Biophys. J. 2003, 84, 1252.

[65] E. T. Herruzo, H. Asakawa, T. Fukuma, R. Garcia, Nanoscale 2013, 5, 2678.

[66] D. J. Müller, Y. F. Dufrêne, Nat. Nanotechnol. 2008, 3, 261.

[67] D. J. Müller, Y. F. Dufrêne, Trends Cell Biol. 2011, 21, 461.

[68] Y. F. Dufrêne, D. Martínez-Martín, I. Medalsy, D. Alsteens, D. J. Müller, Nat. Methods 2013, $10,847$.

[69] S. Kasas, G. Longo, G. Dietler, J. Phys. D. Appl. Phys. 2013, 46, 133001.

[70] H. R. Wirtz, L. G. Dobbs, Respir. Physiol. 2000, 119, 1.

[71] S. E. Cross, Y.-S. Jin, J. Rao, J. K. Gimzewski, Nat. Nanotechnol. 2007, 2, 780.

[72] J. G. Goetz, S. Minguet, I. Navarro-Lérida, J. J. Lazcano, R. Samaniego, E. Calvo, M. Tello, T. Osteso-Ibáñez, T. Pellinen, A. Echarri, A. Cerezo, A. J. P. Klein-Szanto, R. Garcia, P. J. Keely, P. Sánchez-Mateos, E. Cukierman, M. a. Del Pozo, Cell 2011, 146, 148.

[73] B. J. Rodriguez, R. Proksch, P. Maksymovych, S. V Kalinin, Handbook of Nanoscopy, Vol. 1,2, Wiley-VCH Verlag \& Co. KgAa, Weinheim, Germany 2012, 539.

[74] M. Stolz, R. Raiteri, A. U. Daniels, M. R. VanLandingham, W. Baschong, U. Aebi, Biophys. J. 2004, 86, 3269.

[75] D. Leckband, Annu. Rev. Biophys. Biomol. Struct. 2000, 29, 1.

[76] K. C. Neuman, A. Nagy, Nat. Methods 2008, 5, 491.

[77] N. de Souza, Nat. Methods 2012, 9, 873.

[78] D. M. Ebenstein, L. A. Pruitt, J. Biomed. Mater. Res. A 2004, 69, 222.

[79] D. M. Ebenstein, L. A. Pruitt, Nano Today 2006, 1, 26. 
[80] O. Chaudhuri, S. H. Parekh, W. A. Lam, D. A. Fletcher, Nat. Methods 2009, 6, 383.

[81] M. P. Stewart, A. W. Hodel, A. Spielhofer, C. J. Cattin, D. J. Müller, J. Helenius, Methods 2013, 60, 186.

[82] J. Friedrichs, K. R. Legate, R. Schubert, M. Bharadwaj, C. Werner, D. J. Müller, M. Benoit, Methods 2013, 60, 169.

[83] A. R. Harris, G. T. Charras, Nanotechnology 2011, 22, 345102.

[84] R. Kassies, K. O. Van Der Werf, A. Lenferink, C. N. Hunter, J. D. Olsen, V. Subramaniam, C. Otto, in J. Microsc., 2005, 217, 109-116.

[85] E. Hecht, K. Thompson, M. Frick, O. H. Wittekindt, P. Dietl, B. Mizaikoff, C. Kranz, Anal. Chem. 2012, 84, 5716.

[86] N. A. Geisse, S. P. Sheehy, K. K. Parker, In Vitro Cell. Dev. Biol. Anim. 2009, 45, 343.

[87] M.-A. Bray, N. A. Geisse, K. K. Parker, Biophys. J. 2007, 92, 4433.

[88] J. G. McGarry, P. Maguire, V. a. Campbell, B. C. O’Connell, P. J. Prendergast, S. P. Jarvis, J. Orthop. Res. 2008, 26, 513.

[89] C. Rotsch, M. Radmacher, Biophys. J. 2000, 78, 520.

[90] J. Chen, M. A. Birch, S. J. Bull, J. Mater. Sci. Mater. Med. 2010, 21, 277.

[91] R. E. Mahaffy, S. Park, E. Gerde, J. Käs, C. K. Shih, Biophys. J. 2004, 86, 1777.

[92] R. J. Young, L. P., J. Eng. Mater. Technol. 1991, 104, 297.

[93] C. A. Clifford, M. P. Seah, Appl. Surf. Sci. 2005, 252, 1915.

[94] H. Hertz, J. für die reine und Angew. Math. 1881, 92, 156.

[95] I. N. Sneddon, Int. J. Eng. Sci. 1965, 3, 47.

[96] H. Ladjal, J. L. Hanus, A. Pillarisetti, C. Keefer, A. Ferreira, J. P. Desai, IEEE/RSJ Int. Conf. Intell. Robot. Syst. Oct. 2009, St. Louis, MO, US 2009, 1326.

[97] F. Rico, P. Roca-Cusachs, N. Gavara, R. Farré, M. Rotger, D. Navajas, Phys. Rev. E 2005, 72, 021914.

[98] D. C. Lin, F. Horkay, Soft Matter 2008, 4, 669.

[99] B. V. Derjaguin, V. M. Muller, Y. P. Toporov, Prog. Surf. Sci. 1994, 45, 131.

[100] K. L. Johnson, K. Kendall, A. D. Roberts, T. R. Society, R. Society, P. Sciences, Proc. R. Soc. Lond. A. Math. Phys. Sci. 1971, 324, 301.

[101] D. Maugis, J. Colloid Interface Sci. 1992, 150, 243. 
[102] D. S. Dugdale, J. Mech. Phys. Solids 1960, 8, 100.

[103] D. C. Lin, E. K. Dimitriadis, F. Horkay, J. Biomech. Eng. 2007, 129, 904.

[104] E. Barthel, J. Phys. D. Appl. Phys. 2008, 41, 163001.

[105] K. L. Johnson, J. A. Greenwood, J. Colloid Interface Sci. 1997, 192, 326.

[106] S. Iyer, R. M. Gaikwad, V. Subba-Rao, C. D. Woodworth, I. Sokolov, Nat. Nanotechnol. 2009, 4, 389.

[107] J. A. C. Santos, L. M. Rebêlo, A. C. Araujo, E. B. Barros, J. S. de Sousa, Soft Matter 2012, 8,4441 .

[108] A. Ikai, Philos. Trans. R. Soc. Lond. B. Biol. Sci. 2008, 363, 2163.

[109] D. C. Lin, E. K. Dimitriadis, F. Horkay, in ASME 2007 Summer Bioeng. Conf., 2007, pp. 1-2.

[110] W. C. Oliver, G. M. Pharr, J. Mater. Res. 1992, 7, 1564.

[111] J. Xu, J. Y. Rho, S. R. Mishra, Z. Fan, J. Biomed. Mater. Res. A 2003, 67, 719.

[112] J. Chen, Interface Focus 2014, 4, 20130055.

[113] M. R. Bonilla, J. R. Stokes, M. J. Gidley, G. E. Yakubov, Soft Matter 2015, 11, 1281.

[114] K. T. Wan, V. Chan, D. A. Dillard, Colloids Surfaces B Biointerfaces 2003, 27, 241.

[115] R. Mercadé-Prieto, Z. Zhang, J. Microencapsul. 2012, 29, 277.

[116] E. Moeendarbary, A. R. Harris, Wiley Interdiscip. Rev. Syst. Biol. Med. 2014, 6, 371.

[117] P. K. Hansma, J. P. Cleveland, M. Radmacher, D. A. Walters, P. E. Hillner, M. Bezanilla, M. Fritz, D. Vie, H. G. Hansma, C. B. Prater, J. Massie, L. Fukunaga, J. Gurley, V. Elings, Appl. Phys. Lett. 1994, 64, 1738.

[118] C. A. J. Putman, K. O. Van Der Werf, B. G. De Grooth, N. F. Van Hulst, J. Greve, Appl. Phys. Lett. 1994, 64, 2454.

[119] M. Radmacher, M. Fritz, C. C. M. Kacher, J. P. Cleveland, P. K. Hansma, Biophys. J. 1996, $70,556$.

[120] S. Tripathy, E. J. Berger, J. Biomech. Eng. 2009, 131, 094507.

[121] B. A. Smith, B. Tolloczko, J. G. Martin, P. Grütter, Biophys. J. 2005, 88, 2994.

[122] M. J. Jaasma, W. M. Jackson, T. M. Keaveny, Ann. Biomed. Eng. 2006, 34, 748.

[123] J. Solon, I. Levental, K. Sengupta, P. C. Georges, P. A. Janmey, Biophys. J. 2007, 93, 4453. 
[124] A. M. Altman, V. Gupta, C. N. Ríos, E. U. Alt, A. B. Mathur, Acta Biomater. 2010, 6, 1388.

[125] S. Steltenkamp, C. Rommel, J. Wegener, A. Janshoff, Small 2006, 2, 1016.

[126] S. Na, A. Trache, J. Trzeciakowski, Z. Sun, G. A. Meininger, J. D. Humphrey, A. T. Rache, J. T. Rzeciakowski, Z. S. Un, G. A. M. Eininger, J. D. H. Umphrey, Ann. Biomed. Eng. 2008, 36, 369.

[127] G. M. Kelly, J. I. Kilpatrick, M. H. van Es, P. P. Weafer, P. J. Prendergast, S. P. Jarvis, J. Biomech. 2011, 44, 1484.

[128] N. I. Nikolaev, T. Müller, D. J. Williams, Y. Liu, J. Biomech. 2014, 47, 625.

[129] S. Vichare, S. Sen, M. M. Inamdar, Soft Matter 2014, 10, 1174.

[130] J. Y. Wong, J. B. Leach, X. Q. Brown, Surf. Sci. 2004, 570, 119.

[131] A. E. Pelling, M. A. Horton, Pflugers Arch. Eur. J. Physiol. 2008, 456, 3.

[132] K. Haase, A. E. Pelling, J. R. Soc. Interface 2014, 12, 20140970.

[133] D. A. Fletcher, R. D. Mullins, Nature 2010, 463, 485.

[134] C. T. Lim, E. H. Zhou, S. T. Quek, J. Biomech. 2006, 39, 195.

[135] E. K. Dimitriadis, F. Horkay, J. Maresca, B. Kachar, R. S. Chadwick, Biophys. J. 2002, $82,2798$.

[136] J. Alcaraz, L. Buscemi, M. Puig-de-Morales, Langmuir 2002, 18, 716.

[137] A. Vinckier, G. Semenza, FEBS Lett. 1998, 430, 12.

[138] A. B. Mathur, A. M. Collinsworth, W. M. Reichert, W. E. Kraus, G. A. Truskey, J. Biomech. 2001, 34, 1545.

[139] A. J. Engler, L. Richert, J. Y. Wong, C. Picart, D. E. Discher, Surf. Sci. 2004, 570, 142.

[140] J. H. Hoh, C. A. Schoenenberger, J. Cell Sci. 1994, 107, 1105.

[141] L. Xiao, M. Tang, Q. Li, A. Zhou, Anal. Methods 2013, 5, 874.

[142] P. P. Weafer, J. P. McGarry, M. H. Van Es, J. I. Kilpatrick, W. Ronan, D. R. Nolan, S. P. Jarvis, Rev. Sci. Instrum. 2012, 83, 093709.

[143] Z. L. Zhou, A. H. W. Ngan, B. Tang, A. X. Wang, J. Mech. Behav. Biomed. Mater. 2012, 8, 134.

[144] T. Beléndez, C. Neipp, A. Beléndez, Eur. J. Phys. 2002, 23, 371.

[145] H.-J. Butt, M. Jaschke, Nanotechnology 1995, 6, 1. 
[146] N. Guz, M. Dokukin, V. Kalaparthi, I. Sokolov, Biophys. J. 2014, 107, 564.

[147] D. Y. C. Chan, R. G. Horn, J. Chem. Phys. 1985, 83, 5311.

[148] A. C. Fischer-Cripps, Introduction to Contact Mechanics, Springer US, Boston, MA, 2007.

[149] M. J. Higgins, R. Proksch, J. E. Sader, M. Polcik, S. Mc Endoo, J. P. Cleveland, S. P. Jarvis, Rev. Sci. Instrum. 2006, 77, 1.

[150] D. A. Walters, J. P. Cleveland, N. H. Thomson, P. K. Hansma, M. A. Wendman, G. Gurley, V. Elings, Rev. Sci. Instrum. 1996, 67, 3583.

[151] R. Proksch, T. E. Schäffer, J. P. Cleveland, R. C. Callahan, M. B. Viani, Nanotechnology 2004, 15, 1344.

[152] J. E. Sader, J. Lu, P. Mulvaney, Rev. Sci. Instrum. 2014, 85, 113702.

[153] J. E. Sader, J. W. M. Chon, P. Mulvaney, Rev. Sci. Instrum. 1999, 70, 3967.

[154] J. E. Sader, J. A. Sanelli, B. D. Adamson, J. P. Monty, X. Wei, S. A. Crawford, J. R. Friend, I. Marusic, P. Mulvaney, E. J. Bieske, Rev. Sci. Instrum. 2012, 83, 103705.

[155] S. L. Crick, F. C.-P. P. Yin, Biomech. Model. Mechanobiol. 2007, 6, 199.

[156] D. C. Lin, E. K. Dimitriadis, F. Horkay, J. Biomech. Eng. 2007, 129, 430.

[157] D. Rudoy, S. G. Yuen, R. D. Howe, P. J. Wolfe, J. R. Stat. Soc. Ser. C Appl. Stat. 2010, $59,573$.

[158] E. A-Hassan, W. F. Heinz, M. D. Antonik, N. P. D’Costa, S. Nageswaran, C. A. Schoenenberger, J. H. Hoh, Biophys. J. 1998, 74, 1564.

[159] P. Carl, H. Schillers, Pflugers Arch. 2008, 457, 551.

[160] J. S. Villarrubia, J. Res. Natl. Inst. Stand. Technol. 1997, 102, 425.

[161] J. G. McGarry, P. J. Prendergast, Eur. Cell. Mater. 2004, 7, 27.

[162] A. J. Maniotis, C. S. Chen, D. E. Ingber, Proc. Natl. Acad. Sci. U. S. A. 1997, 94, 849.

[163] A. Jafari Bidhendi, R. K. Korhonen, Comput. Math. Methods Med. 2012, 2012, 192618.

[164] W. R. Trickey, F. P. T. Baaijens, T. A. Laursen, L. G. Alexopoulos, F. Guilak, J. Biomech. 2006, 39, 78.

[165] N. Nijenhuis, X. Zhao, A. Carisey, C. Ballestrem, B. Derby, Biophys. J. 2014, 107, 1502. 
[166] S. Habelitz, S. J. Marshall, G. W. Marshall, M. Balooch, Arch. Oral Biol. 2001, 46, 173.

[167] P. Polyakov, C. Soussen, J. Duan, J. F. L. Duval, D. Brie, G. Francius, PLoS One 2011, 6, e18887.

[168] L. Chopinet, C. Formosa, M. P. Rols, R. E. Duval, E. Dague, Micron 2013, 48, 26.

[169] A. J. Engler, F. Rehfeldt, S. Sen, D. E. Discher, Methods Cell Biol. 2007, 83, 521.

[170] J. M. Maloney, D. Nikova, F. Lautenschläger, E. Clarke, R. Langer, J. Guck, K. J. Van Vliet, Biophys. J. 2010, 99, 2479.

[171] K. S. Kolahi, M. R. K. Mofrad, Wiley Interdiscip. Rev. Syst. Biol. Med. 2010, 2, 625.

[172] M. Groer, Advanced Pathophysiology. Application to Clinical Practice, Lippincott Williams \& Wilkins, Philadelphia 2001.

[173] M. J. Paszek, N. Zahir, K. R. Johnson, J. N. Lakins, G. I. Rozenberg, A. Gefen, C. A. Reinhart-King, S. S. Margulies, M. Dembo, D. Boettiger, D. A. Hammer, V. M. Weaver, Cancer Cell 2005, 8, 241.

[174] A. N. Ketene, E. M. Schmelz, P. C. Roberts, M. Agah, Nanomedicine Nanotechnology, Biol. Med. 2012, 8, 93.

[175] L. M. Rebelo, J. S. de Sousa, J. Mendes Filho, M. Radmacher, Nanotechnology 2013, $24,055102$.

[176] N. Ruthardt, D. C. Lamb, C. Bräuchle, Mol. Ther. 2011, 19, 1199.

[177] E. Evans, W. Rawicz, Phys. Rev. Lett. 1990, 64, 2094.

[178] J. Y. Shao, R. M. Hochmuth, Biophys. J. 1996, 71, 2892.

[179] M. M. Brandão, a Fontes, M. L. Barjas-Castro, L. C. Barbosa, F. F. Costa, C. L. Cesar, S. T. O. Saad, Eur. J. Haematol. 2003, 70, 207.

[180] J. H. C. Wang, J. S. Lin, Biomech. Model. Mechanobiol. 2007, 6, 361.

[181] B. Sabass, M. L. Gardel, C. M. Waterman, U. S. Schwarz, Biophys. J. 2008, 94, 207.

[182] D. Kilinc, G. U. Lee, Integr. Biol. (Camb). 2014, 6, 27.

[183] M. Tanase, N. Biais, M. Sheetz, Methods Cell Biol. 2007, 83, 473.

[184] E. U. Azeloglu, K. D. Costa, Methods Mol. Biol. 2011, 736, 303.

[185] B. P. Jena, H. Hörber, Atomic Force Microscopy in Cell Biology, Academic Press, San Diego 2002.

[186] R. I. Clyman, K. a McDonald, R. H. Kramer, Circ. Res. 1990, 67, 175. 
[187] M. Plomp, T. J. Leighton, K. E. Wheeler, H. D. Hill, A. J. Malkin, Proc. Natl. Acad. Sci. U. S. A. 2007, 104, 9644.

[188] G. E. Fantner, R. J. Barbero, D. S. Gray, A. M. Belcher, Nat. Nanotechnol. 2010, 5 , 280.

[189] R. Nowakowski, P. Luckham, P. Winlove, Biochim. Biophys. Acta-Biomembr. 2001, $1514,170$.

[190] J. L. Maciaszek, G. Lykotrafitis, J. Biomech. 2011, 44, 657.

[191] Y. F. Dufrêne, Trends Microbiol. 2015, 23, 376.

[192] Y. F. Dufrêne, C. J. P. Boonaert, H. C. van der Mei, H. J. Busscher, P. G. Rouxhet, Ultramicroscopy 2001, 86, 113.

[193] P. C. Y. Lau, J. R. Dutcher, T. J. Beveridge, J. S. Lam, Biophys. J. 2009, 96, 2935.

[194] L. Kailas, E. C. Ratcliffe, E. J. Hayhurst, M. G. Walker, S. J. Foster, J. K. Hobbs, Ultramicroscopy 2009, 109, 775.

[195] M. J. Rosenbluth, W. A. Lam, D. A. Fletcher, Biophys. J. 2006, 90, 2994.

[196] L. Ng, H. H. Hung, A. Sprunt, S. Chubinskaya, C. Ortiz, A. Grodzinsky, J. Biomech. 2007, 40, 1011.

[197] Y. F. Dufrêne, Micron 2001, 32, 153.

[198] Y. F. Dufrêne, J. Bacteriol. 2002, 184, 5205.

[199] Y. F. Dufrêne, Nat. Protoc. 2008, 3, 1132.

[200] A. Touhami, B. Nysten, Y. Dufrêne, Langmuir 2003, 19, 4539.

[201] V. Dupres, F. D. Menozzi, C. Locht, B. H. Clare, N. L. Abbott, S. Cuenot, C. Bompard, D. Raze, Y. F. Dufrêne, Nat. Methods 2005, 2, 515.

[202] E. Dague, R. Bitar, H. Ranchon, F. Durand, H. M. Yken, J. M. François, Yeast 2010, $27,673$.

[203] D. B. Flagfeldt, V. Siewers, L. Huang, J. Nielsen, Yeast 2009, 26, 545.

[204] S. Kasas, A. Ikai, Biophys. J. 1995, 68, 1678.

[205] J. I. Kilpatrick, A. Gannepalli, J. P. Cleveland, S. P. Jarvis, Rev. Sci. Instrum. 2009, 80, 023701.

[206] P. Maguire, J. I. Kilpatrick, G. Kelly, P. J. Prendergast, V. A. Campbell, B. C. O'Connell, S. P. Jarvis, HFSP J. 2007, 1, 181.

[207] N. J. Tao, S. M. Lindsay, S. Lees, Biophys. J. 1992, 63, 1165. 
[208] J. E. Ortega, P. Barrón-González, E. Pérez, A. López-Aldrete, in Microsc. Adv. Sci. Res. Educ. (Ed.: A. Méndez-Vilas), Formatex Research Center, Zurbarán 2014, pp. 131-140.

[209] J. Liu, N. Sun, M. A. Bruce, J. C. Wu, M. J. Butte, PLoS One 2012, 7, e37559.

[210] B. S. Elkin, E. U. Azeloglu, K. D. Costa, B. Morrison, J. Neurotrauma 2007, 24, 812.

[211] H. Jin, Q. Liang, T. Chen, X. Wang, PLoS One 2014, 9, e91611.

[212] C. Braunsmann, J. Seifert, J. Rheinlaender, T. E. Schäffer, Rev. Sci. Instrum. 2014, 85, 073703.

[213] E. Henderson, P. Haydon, D. Sakaguchi, Science 1992, 257, 1944.

[214] D. Pesen, J. H. Hoh, Biophys. J. 2005, 88, 670.

[215] L. M. Rebelo, J. S. De Sousa, T. M. Santiago, J. M. Filho, in Microsc. Adv. Sci. Res. Educ. (Ed.: A. Méndez-Vilas), Formatex Research Center, Zurbarán 2014, pp. 141152.

[216] M. Khan, H. Soni, A. K. Sood, Appl. Phys. Lett. 2009, 95, 233703.

[217] S. Kumar, V. M. Weaver, Cancer Metastasis Rev. 2009, 28, 113.

[218] K. Pogoda, J. Jaczewska, J. Wiltowska-Zuber, O. Klymenko, K. Zuber, M. Fornal, M. Lekka, Eur. Biophys. J. 2012, 41, 79.

[219] L. Andolfi, E. Bourkoula, E. Migliorini, A. Palma, A. Pucer, M. Skrap, G. Scoles, A. P. Beltrami, D. Cesselli, M. Lazzarino, PLoS One 2014, 9, e112582.

[220] J. Rother, H. Nöding, I. Mey, A. Janshoff, Open Biol. 2014, 4, 140046.

[221] S. Suresh, J. Spatz, J. P. Mills, A. Micoulet, M. Dao, C. T. Lim, M. Beil, T. Seufferlein, Acta Biomater. 2005, 1, 15.

[222] J. Guck, S. Schinkinger, B. Lincoln, F. Wottawah, S. Ebert, M. Romeyke, D. Lenz, H. M. Erickson, R. Ananthakrishnan, D. Mitchell, J. Käs, S. Ulvick, C. Bilby, Biophys. J. 2005, $88,3689$.

[223] H. Liu, J. Wen, Y. Xiao, J. Liu, S. Hopyan, M. Radisic, C. A. Simmons, Y. Sun, ACS Nano 2014, 8, 3821.

[224] E. L. Florin, V. T. Moy, H. E. Gaub, Science 1994, 264, 415.

[225] R. Popeski-Dimovski, Carbohydr. Polym. 2015, 123, 146.

[226] B. Liu, W. Chen, C. Zhu, Annu. Rev. Phys. Chem. 2014, 66, 150112150056003.

[227] P. Hinterdorfer, Y. F. Dufrêne, Nat. Methods 2006, 3, 347. 
[228] P. Hinterdorfer, W. Baumgartner, H. J. Gruber, K. Schilcher, H. Schindler, Proc. Natl. Acad. Sci. U. S. A. 1996, 93, 3477.

[229] J. Jaczewska, M. H. Abdulreda, C. Y. Yau, M. M. Schmitt, I. Schubert, P.-O. Berggren, C. Weber, R. R. Koenen, V. T. Moy, E. P. Wojcikiewicz, J. Leukoc. Biol. 2014, 95 , 265.

[230] J. Helenius, C.-P. Heisenberg, H. E. Gaub, D. J. Muller, J. Cell Sci. 2008, 121, 1785.

[231] J. Friedrichs, J. Helenius, D. J. Muller, Nat. Protoc. 2010, 5, 1353.

[232] A. Beaussart, S. El-Kirat-Chatel, P. Herman, D. Alsteens, J. Mahillon, P. Hols, Y. F. Dufrêne, Biophys. J. 2013, 104, 1886.

[233] A. Beaussart, S. El-Kirat-Chatel, Nat. Protoc. 2014, 9, 1049.

[234] G. Zeng, T. Müller, R. L. Meyer, Langmuir 2014, 30, 4019.

[235] J. Klein, Proc. Inst. Mech. Eng. Part J J. Eng. Tribol. 2006, 220, 691.

[236] U. Raviv, S. Giasson, N. Kampf, J.-F. Gohy, R. Jérôme, J. Klein, Nature 2003, 425, 163.

[237] S. Lee, N. Spencer, Science 2008, 319, 575.

[238] L. Ma, A. Gaisinskaya-kipnis, N. Kampf, J. Klein, Nat. Commun. 2015, 6, 1.

[239] J. R. Capadona, K. Shanmuganathan, D. J. Tyler, S. J. Rowan, C. Weder, Science 2008, $319,1370$.

[240] S. Iwamoto, W. Kai, A. Isogai, T. Iwata, Biomacromolecules 2009, 10, 2571.

[241] J. B. Thompson, J. H. Kindt, B. Drake, H. G. Hansma, D. E. Morse, P. K. Hansma, Nature 2001, 414, 773.

[242] M. Balooch, I. C. Wu-Magidi, A. Balazs, A. S. Lundkvist, S. J. Marshall, G. W. Marshall, W. J. Siekhaus, J. H. Kinney, J. Biomed. Mater. Res. 1998, 40, 539.

[243] H. Fong, M. Sarikaya, S. N. White, M. L. Snead, Mater. Sci. Eng. C 2000, 7, 119.

[244] E. M. Darling, R. E. Wilusz, M. P. Bolognesi, S. Zauscher, F. Guilak, Biophys. J. 2010, 98, 2848.

[245] R. V Patel, J. J. Mao, Front. Biosci. 2003, 8, a18.

[246] P. Radhakrishnan, N. Lewis, J. Mao, Ann. Biomed. Eng. 2004, 32, 284.

[247] M. A. McLeod, R. E. Wilusz, F. Guilak, J. Biomech. 2013, 46, 586.

[248] C. A. Grant, N. H. Thomson, M. D. Savage, H. W. Woon, D. Greig, J. Mech. Behav. Biomed. Mater. 2011, 4, 535. 
[249] C. Braunsmann, C. M. Hammer, J. Rheinlaender, F. E. Kruse, T. E. Schäffer, U. Schlötzer-Schrehardt, Invest. Ophthalmol. Vis. Sci. 2012, 53, 2960.

[250] J. E. Marturano, J. D. Arena, Z. A. Schiller, I. Georgakoudi, C. K. Kuo, Proc. Natl. Acad. Sci. U. S. A. 2013, 110, 6370.

[251] A. J. Heim, W. G. Matthews, T. J. Koob, Appl. Phys. Lett. 2006, 89, 181902.

[252] M. P. E. Wenger, L. Bozec, M. A. Horton, P. Mesquida, Biophys. J. 2007, 93, 1255.

[253] C. A. Grant, D. J. Brockwell, S. E. Radford, N. H. Thomson, Appl. Phys. Lett. 2008, 92, 233902.

[254] C. A. Grant, D. J. Brockwell, S. E. Radford, N. H. Thomson, Biophys. J. 2009, 97, 2985.

[255] P. Fratzl, Collagen, Springer Science+Business Media, LLC, New York, NY, 2008.

[256] M. Minary-Jolandan, M.-F. Yu, Biomacromolecules 2009, 10, 2565.

[257] Z. Zhou, M. Minary-Jolandan, D. Qian, Biomech. Model. Mechanobiol. 2014, 1.

[258] W. Guo, M. T. Frey, N. A. Burnham, Y. Wang, Biophys. J. 2006, 90, 2213.

[259] J. Sanchez-Adams, R. E. Wilusz, F. Guilak, J. Orthop. Res. 2013, 31, 1218.

[260] J. Kwok, S. Grogan, B. Meckes, F. Arce, R. Lal, D. D’Lima, Nanomedicine Nanotechnology, Biol. Med. 2014, 10, 1777.

[261] J. W. M. Beenakker, B. A. Ashcroft, J. H. N. Lindeman, T. H. Oosterkamp, Biophys. J. 2012, 102, 1731.

[262] P. Tracqui, A. Broisat, J. Toczek, N. Mesnier, J. Ohayon, L. Riou, J. Struct. Biol. 2011, $174,115$.

[263] C. K. Chai, L. Speelman, C. W. J. Oomens, F. P. T. Baaijens, J. Biomech. 2014, 47, 784.

[264] J. A. Last, T. Pan, Y. Ding, C. M. Reilly, K. Keller, T. S. Acott, M. P. Fautsch, C. J. Murphy, P. Russell, Invest. Ophthalmol. Vis. Sci. 2011, 52, 2147.

[265] J. A. Last, S. J. Liliensiek, P. F. Nealey, C. J. Murphy, J. Struct. Biol. 2009, 167, 19.

[266] T. Luque, E. Melo, E. Garreta, J. Cortiella, J. Nichols, R. Farré, D. Navajas, Acta Biomater. 2013, 9, 6852 .

[267] R. Roy, J. P. Desai, Ann. Biomed. Eng. 2014, 42, 1806.

[268] J. I. Lopez, I. Kang, W.-K. You, D. M. McDonald, V. M. Weaver, Integr. Biol. (Camb). 2011, 3, 910. 
[269] V. F. Achterberg, L. Buscemi, H. Diekmann, J. Smith-Clerc, H. Schwengler, J.-J. Meister, H. Wenck, S. Gallinat, B. Hinz, J. Invest. Dermatol. 2014, 134, 1862.

[270] J. R. Tse, A. J. Engler, Curr. Protoc. Cell Biol. 2010, Chapter 10, Unit 10.16.

[271] N. Zaari, P. Rajagopalan, S. K. Kim, A. J. Engler, J. Y. Wong, Adv. Mater. 2004, 16, 2133.

[272] M. Radmacher, M. Fritz, P. K. Hansma, Biophys. J. 1995, 69, 264.

[273] J. Domke, M. Radmacher, Langmuir 1998, 14, 3320.

[274] S. S. Soofi, J. A. Last, S. J. Liliensiek, P. F. Nealey, C. J. Murphy, J. Struct. Biol. 2009, 167, 216.

[275] K. Ghosh, Z. Pan, E. Guan, S. Ge, Y. Liu, T. Nakamura, X.-D. Ren, M. Rafailovich, R. A. F. Clark, Biomaterials 2007, 28, 671.

[276] A. M. Kloxin, J. A. Benton, K. S. Anseth, Biomaterials 2010, 31, 1.

[277] A. M. Kloxin, C. J. Kloxin, C. N. Bowman, K. S. Anseth, Adv. Mater. 2010, 22, 3484.

[278] Z. Drira, V. K. Yadavalli, J. Mech. Behav. Biomed. Mater. 2013, 18, 20.

[279] A. M. Kloxin, A. M. Kasko, C. N. Salinas, K. S. Anseth, Science 2009, 324, 59.

[280] M. Guvendiren, J. A. Burdick, Nat. Commun. 2012, 3, 792.

[281] B. Anczykowski, B. Gotsmann, Appl. Surf. Sci. 1999, 376.

[282] A. F. Payam, J. R. Ramos, R. Garcia, ACS Nano 2012, 6, 4663.

[283] A. Rosa-Zeiser, E. Weilandt, S. Hild, O. Marti, Meas. Sci. Technol. 1997, 8, 1333.

[284] U. Rabe, W. Arnold, Appl. Phys. Lett. 1994, 64, 1493.

[285] U. Rabe, S. Amelio, E. Kester, V. Scherer, Ultrasonics 2000, 38, 430.

[286] U. Rabe, S. Amelio, M. Kopycinska, S. Hirsekorn, M. Kempf, M. Göken, W. Arnold, Surf. Interface Anal. 2002, 33, 65.

[287] K. Yamanaka, H. Ogiso, O. Kolosov, Appl. Phys. Lett. 1994, 64, 178.

[288] M. E. Dokukin, I. Sokolov, Langmuir 2012, 28, 16060.

[289] M.-K. Sewell-Loftin, C. B. Brown, H. S. Baldwin, W. D. Merryman, J. Heart Valve Dis. 2012, 21, 513.

[290] J. Adamcik, A. Berquand, R. Mezzenga, Appl. Phys. Lett. 2011, 98, 193701. 
[291] K. Sweers, K. van der Werf, M. Bennink, V. Subramaniam, Nanoscale Res. Lett. 2011, 6, 270.

[292] B. D. Huey, Annu. Rev. Mater. Res. 2007, 37, 351.

[293] M. Kocun, A. Labuda, A. Gannepalli, R. Proksch, 2014, arXiv:1410.3311.

[294] K. Wadu-Mesthrige, N. Amro, Appl. Surf. Sci. 2001, 176, 391.

[295] J. Shin, B. J. Rodriguez, A. P. Baddorf, T. Thundat, E. Karapetian, M. Kachanov, A. Gruverman, S. V. Kalinin, J. Vac. Sci. Technol. B Microelectron. Nanom. Struct. 2005, $23,2102$.

[296] S. V Kalinin, B. J. Rodriguez, J. Shin, S. Jesse, V. Grichko, T. Thundat, A. P. Baddorf, A. Gruverman, Ultramicroscopy 2006, 106, 334.

[297] X. Zhou, H. Miao, F. Li, Nanoscale 2013, 5, 11885.

[298] B. Zhang, Q. Cheng, M. Chen, W. Yao, M. Qian, B. Hu, Ultrasound Med. Biol. 2012, 38,1383 .

[299] A. Bhattacharya, S. Banerjee, Micron 2014, 60, 1.

[300] J. P. Killgore, D. G. Yablon, A. H. Tsou, A. Gannepalli, P. A. Yuya, J. A. Turner, R. Proksch, D. C. Hurley, Langmuir 2011, 27, 13983.

[301] G. Stan, S. D. Solares, Beilstein J. Nanotechnol. 2014, 5, 278.

[302] G. Stan, S. W. King, R. F. Cook, Nanotechnology 2012, 23, 215703.

[303] D. Yablon, A. Gannepalli, R. Proksch, Macromolecules 2012, 45, 4163.

[304] L. Collins, A. Tselev, S. Jesse, M. B. Okatan, R. Proksch, J. P. Mathews, G. D. Mitchell, B. J. Rodriguez, S. V Kalinin, I. N. Ivanov, Nanotechnology 2014, 25, 435402.

[305] B. J. Rodriguez, C. Callahan, S. V Kalinin, R. Proksch, Nanotechnology 2007, 18, 475504.

[306] A. Gannepalli, D. G. Yablon, A. H. Tsou, R. Proksch, Nanotechnology 2013, 24, 159501.

[307] T. Li, K. Zeng, Nanoscale 2014, 6, 2177.

[308] J. P. Killgore, D. C. Hurley, Nanotechnology 2012, 23, 055702.

[309] G. S. Shekhawat, V. P. Dravid, Science 2005, 310, 89.

[310] M. Ewald, L. Tetard, C. Elie-Caille, L. Nicod, A. Passian, E. Bourillot, E. Lesniewska, Nanotechnology 2014, 25, 295101. 
[311] L. Tetard, A. Passian, K. T. Venmar, R. M. Lynch, B. H. Voy, G. Shekhawat, V. P. Dravid, T. Thundat, Nat. Nanotechnol. 2008, 3, 501.

[312] L. Tetard, A. Passian, T. Thundat, Nat. Nanotechnol. 2010, 5, 105.

[313] D. Ebeling, B. Eslami, S. D. J. Solares, ACS Nano 2013, 7, 10387.

[314] S. A. Cantrell, J. H. Cantrell, P. T. Lillehei, J. Appl. Phys. 2007, 101, 114324.

[315] J. P. Killgore, J. Y. Kelly, C. M. Stafford, M. J. Fasolka, D. C. Hurley, Nanotechnology 2011, 22, 175706.

[316] O. Sahin, S. Magonov, C. Su, C. F. Quate, O. Solgaard, Nat. Nanotechnol. 2007, 2, 507.

[317] O. Sahin, N. Erina, Nanotechnology 2008, 19, 445717.

[318] R. Garcia, E. T. Herruzo, Nat. Nanotechnol. 2012, 7, 217.

[319] R. Proksch, Appl. Phys. Lett. 2006, 89, 113121.

[320] N. F. Martínez, J. R. Lozano, E. T. Herruzo, F. Garcia, C. Richter, T. Sulzbach, R. Garcia, Nanotechnology 2008, 19, 384011.

[321] C. Dietz, E. T. Herruzo, J. R. Lozano, R. Garcia, Nanotechnology 2011, 22, 125708.

[322] R. Garcia, R. Proksch, Eur. Polym. J. 2013, 49, 1897.

[323] E. T. Herruzo, A. P. Perrino, R. Garcia, Nat. Commun. 2014, 5, 3126.

[324] G. Chawla, S. D. Solares, Appl. Phys. Lett. 2011, 99, 074103.

[325] A. Cartagena, A. Raman, Biophys. J. 2014, 106, 1033.

[326] A. Raman, S. Trigueros, A. Cartagena, A. P. Z. Stevenson, M. Susilo, E. Nauman, S. A. Contera, Nat. Nanotechnol. 2011, 6, 809.

[327] X. Xu, J. Melcher, S. Basak, R. Reifenberger, A. Raman, Phys. Rev. Lett. 2009, 102, 060801.

[328] Y. Shao, J. Fu, Adv. Mater. 2014, 26, 1494.

[329] N. Gjorevski, C. M. Nelson, Biophys. J. 2012, 103, 152.

[330] P. Novak, C. Li, A. I. Shevchuk, R. Stepanyan, M. Caldwell, S. Hughes, T. G. Smart, J. Gorelik, V. P. Ostanin, M. J. Lab, G. W. J. Moss, G. I. Frolenkov, D. Klenerman, Y. E. Korchev, Nat. Methods 2009, 6, 279.

[331] J. Rheinlaender, N. A. Geisse, R. Proksch, T. E. Schäffer, Langmuir 2011, 27, 697. 
[332] B. Harke, J. V. Chacko, H. Haschke, C. Canale, A. Diaspro, Opt. Nanoscopy 2012, 1, 3.

[333] “http://www.brukerafmprobes.com/p-3588-dnp.aspx," (accessed March 2015).

[334] "Bruker Bioscope Resolve - Applications," can be found under https://www.bruker.com/products/surface-analysis/atomic-force-microscopy/bioscoperesolve/applications.html, (accessed March 2015). 


\section{Figures}

a)

Lengthscale (m)

$\mathrm{cm} \quad \mathrm{mm}$

$\mu \mathrm{m}$

$\mathrm{nm}$

Organ

b) Timescale (s)

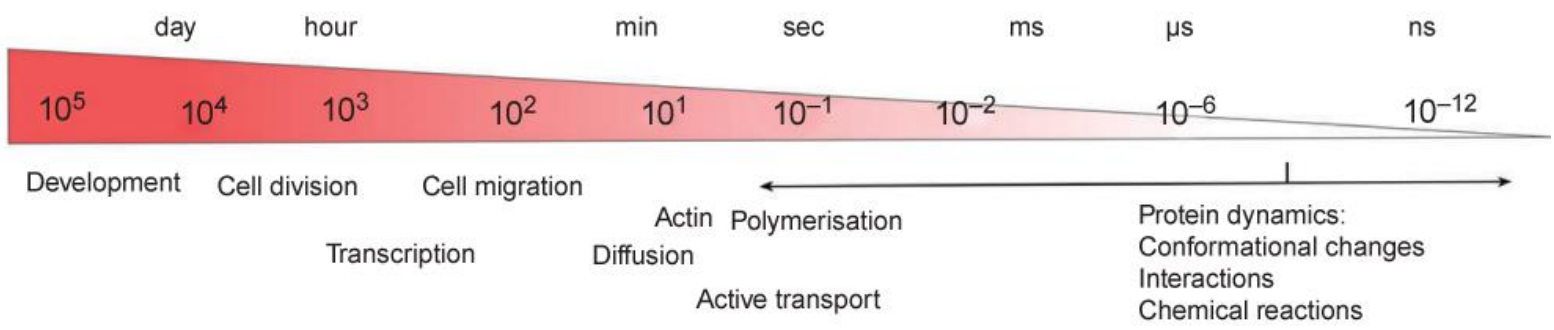

c)

Elastic modulus $(\mathrm{Pa})$

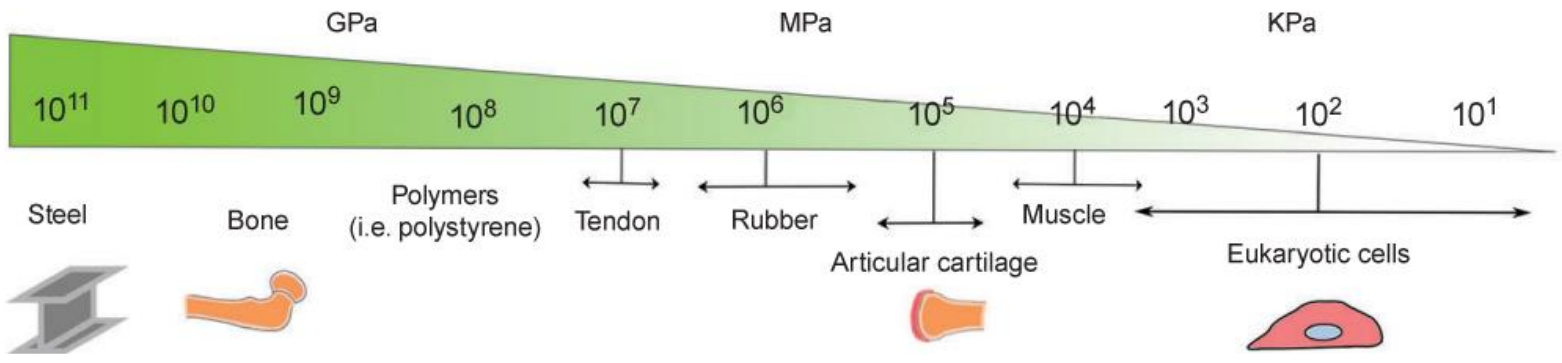

Figure 1. Considerations for mechanical measurements of biosystems showing a) lengthscales involved and hierarchical complexity, b) timescales of different physiological processes, and c) range of elastic modulus for natural and synthetic materials. Reproduced and adapted with permission. ${ }^{[16]}$ Copyright 2014, the authors. 


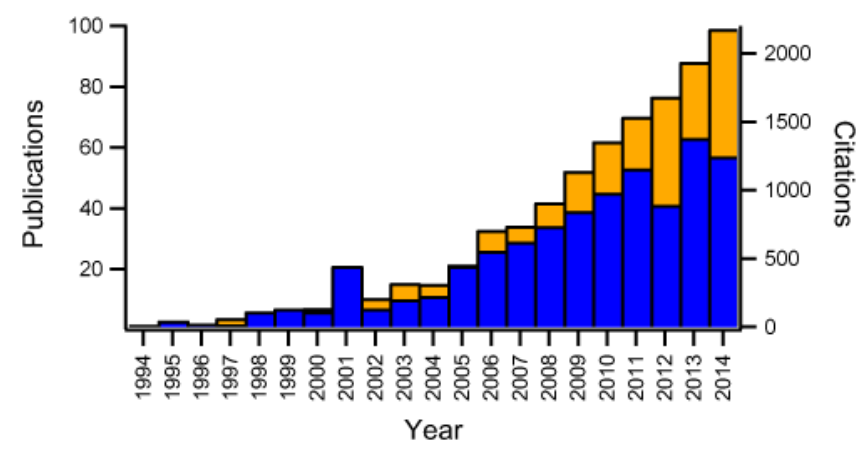

Figure 2. Plot of the number of published articles (blue) and the number of citations per year (yellow) obtained from Scopus using the keywords: AFM, elasticity, and cell. 


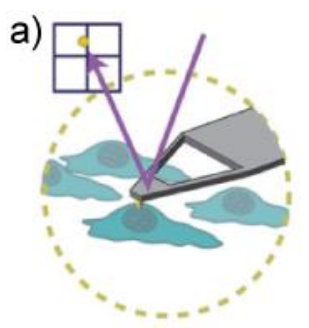

c)

b)

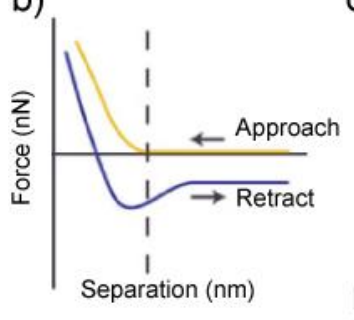

d)
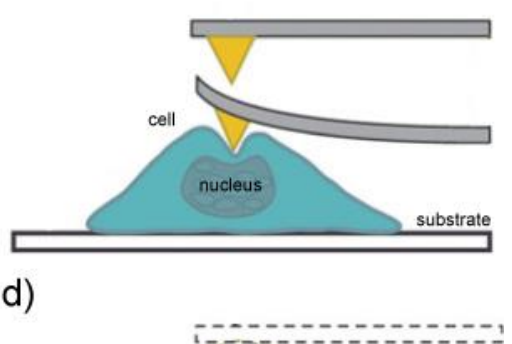

(1)

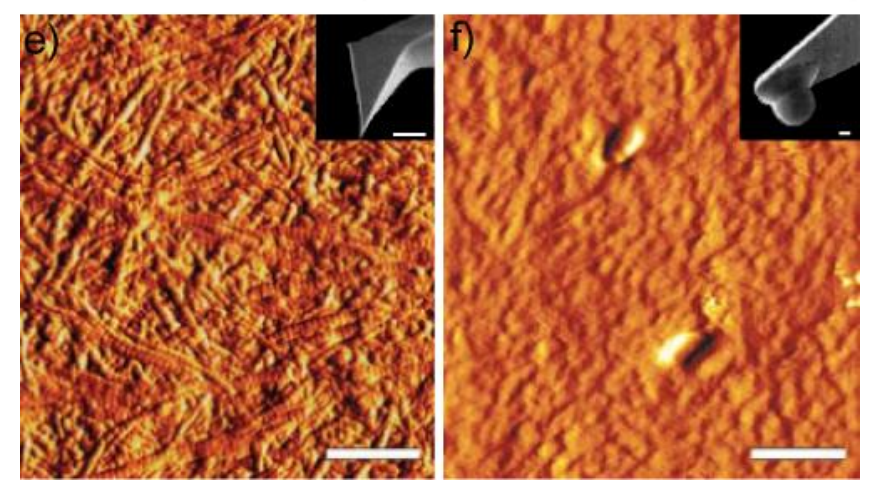

Figure3. a) Basic schematic of an AFM and b) a representative force-distance curve. Side view of an indentation measurement of a cell with a c) pyramidal and d) spherical tip. AFM image of articular cartilage using e) a sharp pyramidal tip (radius $\sim 20 \mathrm{~nm} ; 1 \mu \mathrm{m}$ scale bar) and f) a spherical tip (radius $2.5 \mu \mathrm{m} ; 20 \mu \mathrm{m}$ scale bar). The scale bar for the insets in e) and f) are $1 \mu \mathrm{m}$. a)-d) Reproduced and adapted with permission. ${ }^{[132]}$ Copyright 2015, the authors. e) and f) Reproduced and adapted with permission. ${ }^{[74]}$ Copyright 2004, Elsevier Inc. 


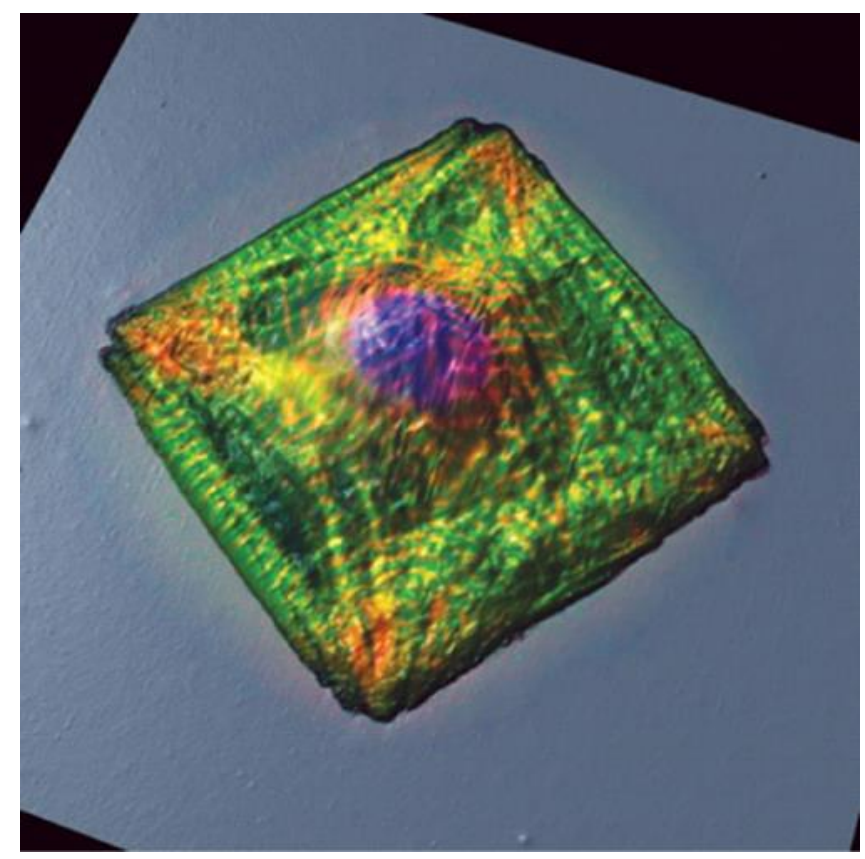

Figure 4. AFM image overlaid with the fluorescence image of a patterned cardiomyocyte. A rat cardiomyocyte was cultured on a micro-contact-printed square island of ECM protein on a polydimethylsiloxane substrate. The cell was fixed and stained for actin (green), sarcomeric alpha-actinin (red), and DNA (blue). After fixation, the cell was scanned by AFM. Overlaid topography and fluorescent images reveal that the actin/alpha-actinin myofibrils and the nucleus are responsible for specific AFM topography. Scan size is $92 \mu \mathrm{m}$. Image courtesy of K. Parker and N. Geisse, Harvard University. 


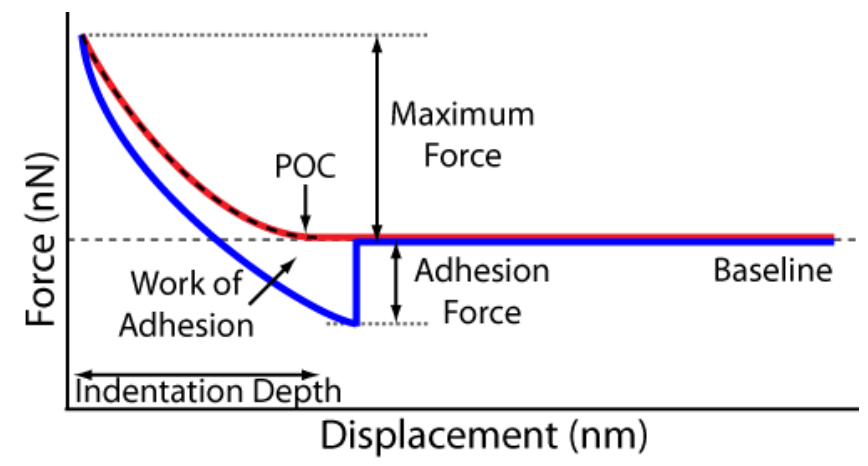

Figure 5. Schematic of a force curve plotted against piezo displacement. The red line is the approach and the blue line is the retract curve. The dashed line on the approach curve indicates the region where fitting models are applied to measure the elastic modulus. 

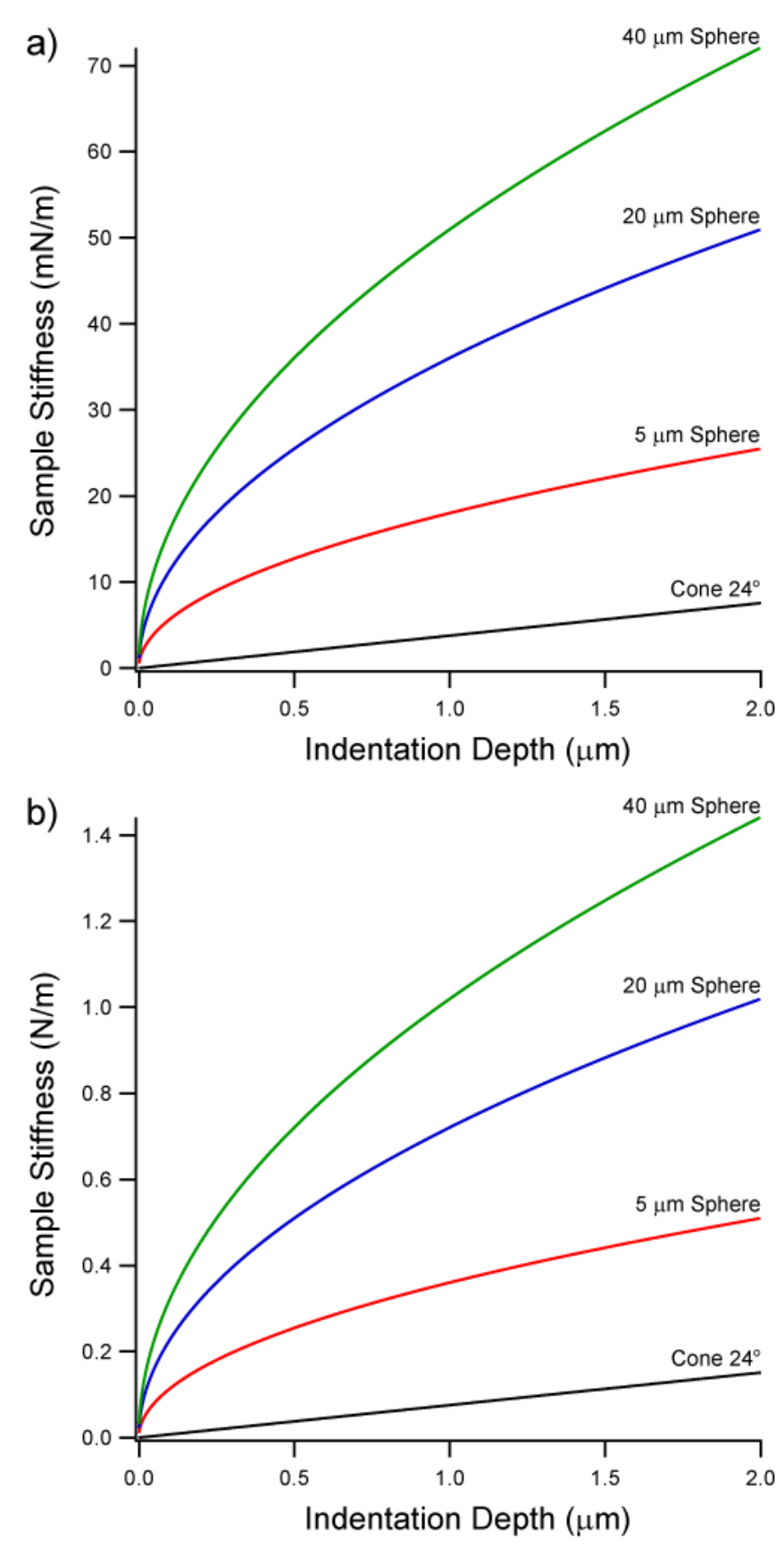

Figure 6. Sample stiffness as a function of indentation depth for various probe geometries for a) $5 \mathrm{kPa}$ and b) $100 \mathrm{kPa}$ samples. Note that sample stiffness scales with contact area. For example: A cantilever having a spring constant of $\sim 0.05 \mathrm{~N} / \mathrm{m}$ should be selected when indenting a $5 \mathrm{kPa}$ sample by $1 \mu \mathrm{m}$ using a $40 \mu \mathrm{m}$ spherical tip whereas a spring constant of $\sim 1$ $\mathrm{N} / \mathrm{m}$ would be required for a $40 \mu \mathrm{m}$ spherical tip indenting a $100 \mathrm{kPa}$ sample by $1 \mu \mathrm{m}$. 
a
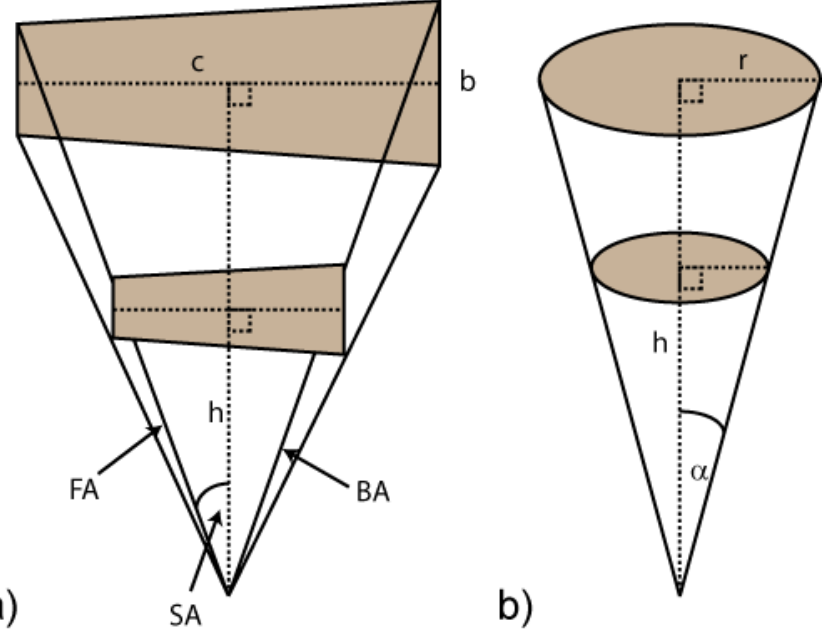

Figure 7. Geometry of a) pyramidal and b) conical AFM tips. For the example of a commonly used cantilever (Bruker DNP) ${ }^{[333]}$ where FA $=15^{\circ} \pm 2.5^{\circ}, \mathrm{BA}=25^{\circ} \pm 2.5^{\circ}$ and SA $=17.5^{\circ} \pm$ $2.5^{\circ}$, Equation 14 yields $\alpha=21.5^{\circ} \pm 1.9^{\circ}$. 

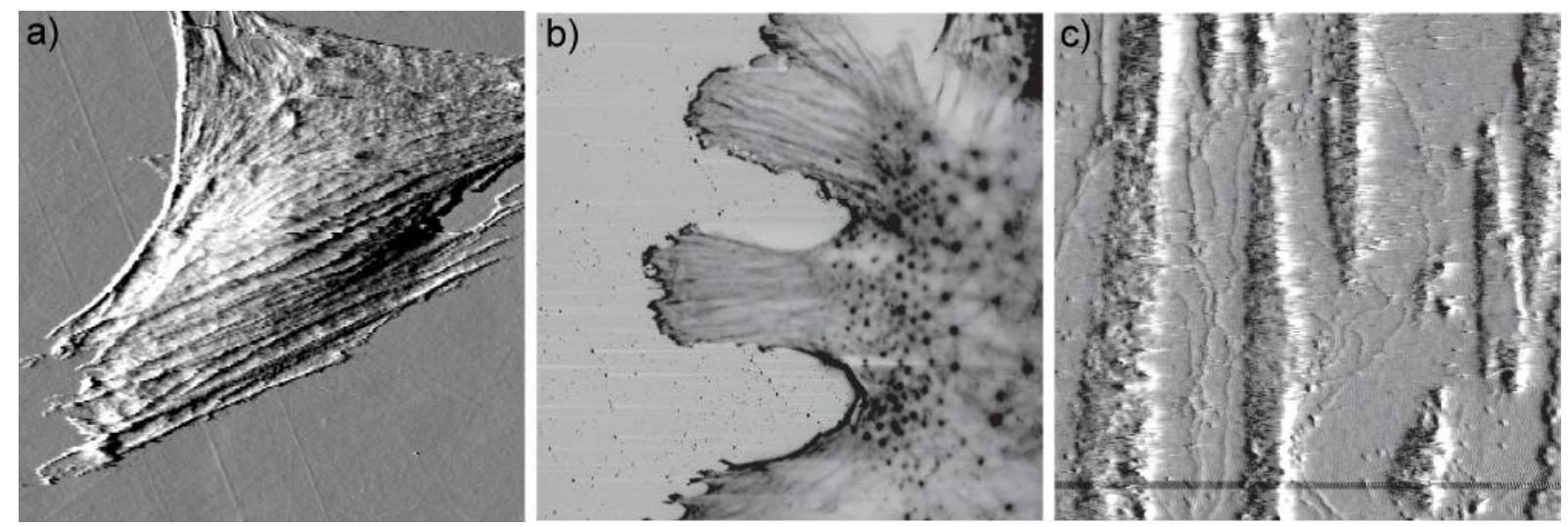

Figure 8. a) Contact mode deflection image of a live MRC-5 cell. The cytoskeleton network is clearly visible. Scan size is $45 \mu \mathrm{m}$. b) Amplitude modulation mode amplitude image for a live mesenchymal stem cell. Scan size is $90 \mu \mathrm{m}$. c) High resolution amplitude modulation mode amplitude image of a mesenchymal stem cell showing cytoskeleton actin bundles and individual actin filaments. Scan size is $14 \mu \mathrm{m}$. b and c) Reproduced and adapted with permission. ${ }^{[206]}$ Copyright 2007, HFSP Publishing. 

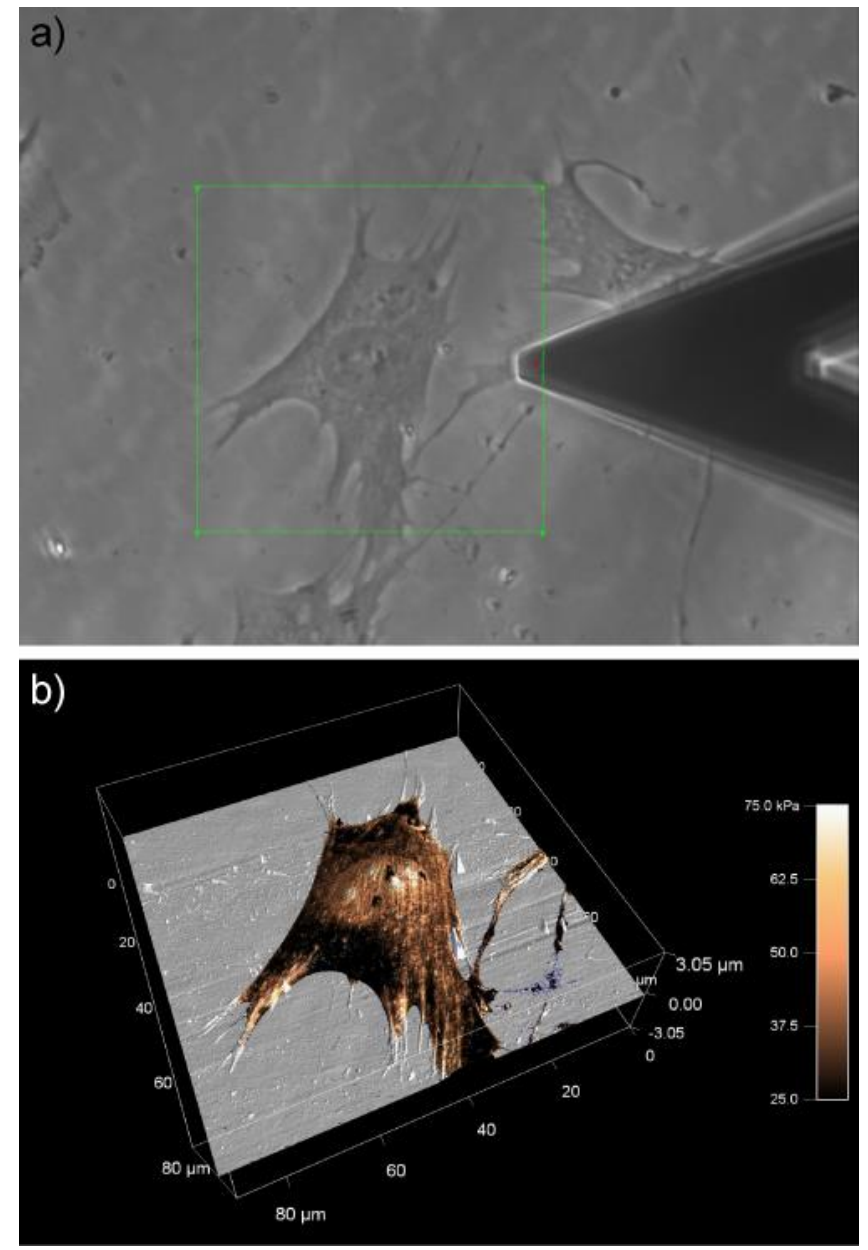

Figure 9. MCR-5 cell studied with a combination of different techniques. a) An optical image obtained with a $40 \times$ objective. The green box indicates the AFM scanning area $(90 \mu \mathrm{m})$. The bottom image is an overlay of two types of data obtained with AFM, on the same cell shown in a). The topographic image is 'painted' with a color scaled image of the Young's modulus of the cell. Each pixel on the image shows the value of the Young's modulus at that specific location. The cell shows stiffness variability across its surface - softer (darker colors) areas of the cytoplasm are contrasted with stiffer (lighter colors) areas in the location of the nucleus. Even stiffer areas are seen in the area of the nucleoli and actin filaments running across the top of the cell. Image courtesy of Sophia Holbauch and Nick Geisse, Asylum Research. 


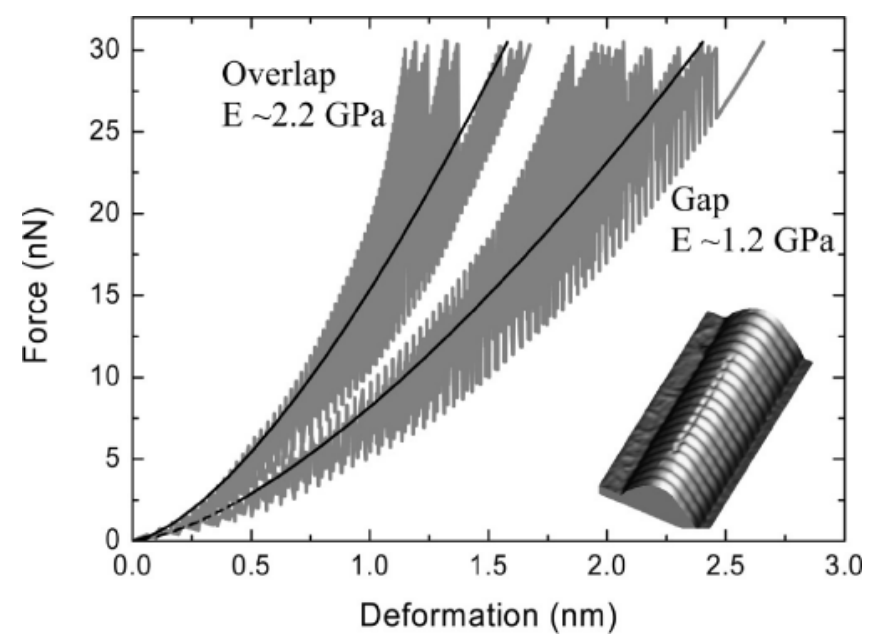

Figure 10. AFM force-indentation curves measured from different locations along a bovine Achilles tendon collagen fibril (inset). The modulus determined from the curves recorded on overlap regions is larger than that determined from the gap regions. The shaded regions show 13 and 15 curves recorded on the overlap and gap regions, respectively, whereas the black lines are fits of the data using the Hertzian contact model. Reproduced with permission. ${ }^{[256]}$ Copyright 2009, American Chemical Society. 


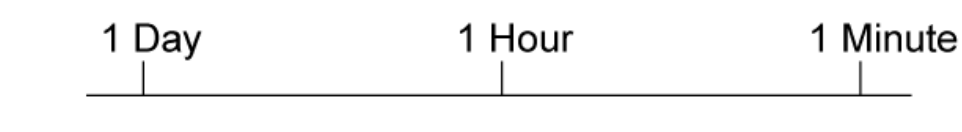

Force Volume (F-V)

Fast Force Volume

Peak Force QMN'M

Dynamic Modes (AM, FM, etc.)

CR / AFAM / UAFM

\begin{tabular}{ll|lllll|ll|l}
\hline $0.1 \mathrm{~Hz}$ & $1 \mathrm{~Hz}$ & $10 \mathrm{~Hz}$ & $100 \mathrm{~Hz}$ & $1 \mathrm{kHz}$ & $10 \mathrm{kHz}$ & $100 \mathrm{kHz}$ & $1 \mathrm{MHz}$ & $10 \mathrm{MHz}$ \\
& & Operating Frequency
\end{tabular}

Figure 11. Operating frequency of various AFM modes of operation which can be used to measure mechanical information. For mapping modes (Force Volume (F-V), Fast Force Volume and Peak Force QNM $^{\mathrm{TM}}$ ) the estimated time taken to acquire a $512 \times 512$ pixel image is indicated on the top axis. Adapted from ${ }^{[334]}$. 

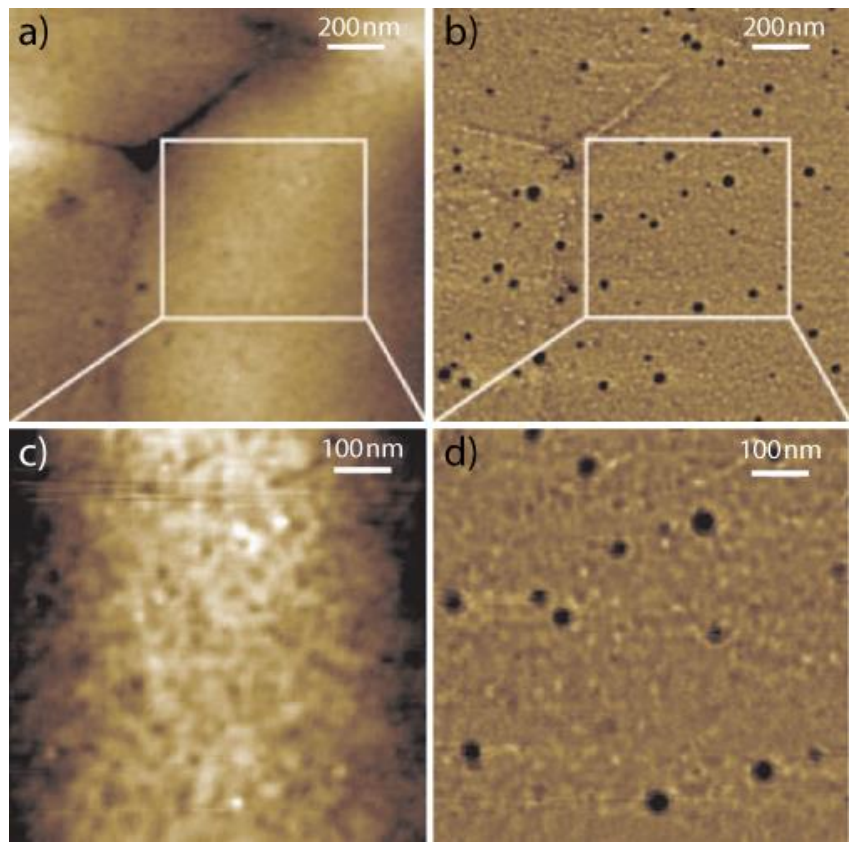

Figure 12. a) and c) AFM topography images and b) and d) scanning near field ultrasonic holography phase images showing the presence of sub-100 nm sized single-walled carbon nanohorns in red blood cells. Reproduced and adapted with permission. ${ }^{[311]}$ Copyright 2008 , Macmillan Publishers Limited. 